\title{
A fungal plant pathogen overcomes conserved broad-spectrum disease resistance by rapid gene loss
}

\author{
Stefan Kusch $^{1}$, Lamprinos Frantzeskakis ${ }^{1,2}$, Birthe D. Lassen ${ }^{1}$, Florian Kümmel ${ }^{1,3}$, Lina Pesch ${ }^{1,4}$, Mirna Barsoum $^{1,5}$, Hongpo \\ $\mathrm{Wu}^{1,6}, \mathrm{Kim}$ D. Walden ${ }^{1}$, and Ralph Panstruga ${ }^{1, \mathbb{}}$

\begin{abstract}
${ }^{1}$ Unit of Plant Molecular Cell Biology, Institute for Biology I, RWTH Aachen University, Worringerweg 1, D-52056 Aachen, Germany ${ }^{2}$ Bayer Crop Science, 700 W Chesterfield Pkwy W, Chesterfield, MO 63017, USA

${ }^{3}$ Department of Plant-Microbe Interactions, Max Planck Institute for Plant Breeding Research, Carl-von-Linné-Weg 10, Cologne D-50829, Germany ${ }^{4}$ Institute for Plant Sciences, University of Cologne, Cologne Biocenter, Zülpicher Str. 47b, D-50674, Cologne, Germany ${ }^{6}$ Institute of Crop Sciences, Chinese Academy of Agricultural Sciences, 100081 Beijing, China
\end{abstract} \\ ${ }^{5}$ Institute of Biochemistry and Molecular Biology, Faculty of Medicine, RWTH Aachen University, Pauwelsstrasse 30, D-52057 Aachen, Germany
}

\begin{abstract}
Hosts and pathogens typically engage in an evolutionary arms race. This also applies to phytopathogenic powdery mildew fungi, which can rapidly overcome plant resistance and perform host jumps. Using experimental evolution, we show that the powdery mildew pathogen Blumeria graminis f.sp. hordei is capable of breaking the agriculturally important broad-spectrum resistance conditioned by barley loss-of-function mlo mutants. Partial mlo virulence is associated with a distinctive pattern of adaptive mutations, including small-sized (8-40 kb) deletions, one of which likely affects spore morphology. The detected mutational spectrum comprises the same loci in at least two independent $\mathbf{m l o}$-virulent isolates, indicating convergent multigenic evolution. This work highlights the dynamic genome evolution of an obligate biotrophic plant pathogen with a transposonenriched genome.
\end{abstract}

Adaptation | Blumeria graminis f.sp. hordei (Bgh) | (Co-)Evolution | Experimental evolution | Fungal genomics | Genome | Mildew resistance Locus $O$ (MLO) | Plant Immunity | Powdery mildew | Rapid evolution

Correspondence:

panstruga@bio1.rwth-aachen.de

\section{Abbreviations}

Bgh, Blumeria graminis f.sp. hordei | bp, base pair | dpi, days postinoculation | hpi, hours post-inoculation | LINE, long interspersed nuclear element | LTR, long terminal repeat | Mla, Mildew resistance locus a | Mlo, Mildew resistance locus $O$ | MMEJ, Microhomology-mediated end joining | NHEJ, Non-homologous end joining | PCA, principal component analysis | PCR, polymerase chain reaction | PEN1/2/3, PENETRATION1/2/3 | RH, relative humidity | RNA-seq, RNA-sequencing | Ror1/Ror2, Required for mlo-specified resistance1/2 | qRT-PCR, quantitative reverse transcriptase-polymerase chain reaction

\section{Introduction}

Pathogens and their hosts are locked in a coevolutionary competition where the host attempts to prevent pathogen infection, while the pathogen adapts to evade host recognition and retain its ability to infect the host. Generalist pathogens infect a broad range of hosts, and their genomes evolve in response to selection by many hosts under diffuse coevolution (1). Specialist pathogens, on the other hand, infect one or few hosts and are engaged in an intimate coevolutionary arms race. The gene-for-gene hypothesis is a paradigm for the arms race between plants and their pathogens (2).
Plants have intracellular nucleotide-binding oligomerization domain (NOD)-like receptors (NLRs) that can recognize pathogen effectors and mount an effective defense response, while pathogens evolve to subvert or circumvent perception (3). Obligate biotrophic pathogens depend on living host cells and, thus, have to evade recognition by NLRs for their very survival and reproduction. Such specialist pathogens often rapidly overcome resistance conferred by effector recognition via cognate host NLRs. For example, the obligate biotrophic barley powdery mildew fungus Blumeria graminis f.sp. hordei $(B g h)$ frequently escapes resistance conditioned by alleles of Mildew locus A (Mla)-encoded NLRs in barley (4). Mla receptors directly bind secreted Bgh effectors, and loss of recognition happens by loss or modification of the cognate effector due to spontaneous mutations in the fungal genome $(5,6)$. In addition, copy number variation contributes to genetic variation and can lead to outbreaks of new strains of filamentous plant pathogens $(7,8)$.

Short generation times, large effective population sizes, and plastic genome architectures are drivers of rapid adaptation in microbial pathogens. Within the lifetime of a plant, pathogens can go through tens or even hundreds of generation cycles, and can produce thousands to millions of individual mito- and meiospores as offspring (9). Hence, the standing genetic variation of the pathogen population is much larger than that of its host by default. This is likely a prerequisite for pathogen survival, since recognition of a single effector suffices to prevent proliferation and reproduction.

The genomes of filamentous plant pathogens frequently exhibit special architectures and features including dispensable accessory chromosomes and hypervariable minichromosomes (10). These are often enriched with transposable elements, carry effector genes, and are otherwise genepoor. Genome compartmentalization known as two-speed architecture is characterized by distinct transposable elementrich regions that mainly contain effector genes that evolve at a faster pace than the rest of the genome $(11,12)$. Intriguingly, some fungal plant pathogens including the cereal powdery mildew pathogen $B$. graminis harbor genomes that are massively inflated by transposable elements $(13,14)$. Trans- 
A

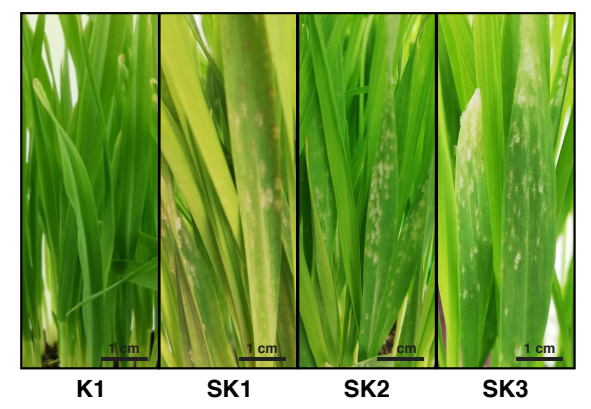

C

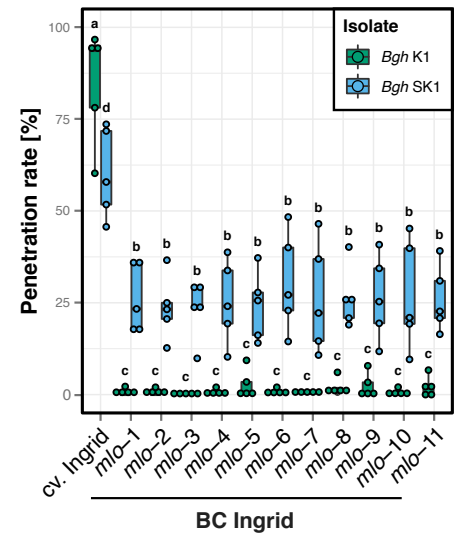

D
B

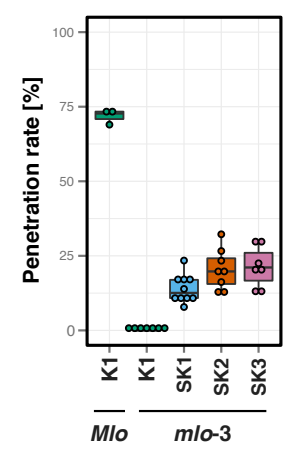

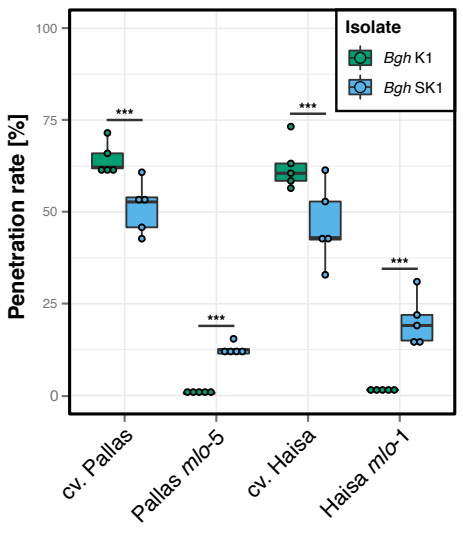

Fig. 1. Isolation of three partially mlo-virulent Bgh isolates. (A) Powdery mildew symptoms caused by Bgh K1 and Bgh SK1, SK2, and SK3 at seven days post-inoculation (dpi) on barley mlo-3 plants. (B) Penetration success in percent [\%] of conidia from Bgh $\mathrm{K} 1$ (green) and the isolates Bgh SK1 (blue), SK2 (orange), and SK3 (purple) on the susceptible barley cv. Ingrid (Mlo) or the backcross Ingrid (BCl) mlo-3 mutant lines. All data points are displayed. (C) Penetration success [\%] of conidia from Bgh K1 (green) and SK1 (blue) on the barley cultivar Ingrid and $11 \mathrm{mlo}$ mutant alleles backcrossed to Ingrid. (D) Penetration success [\%] of conidia from Bgh K1 (green) and SK1 (blue) on barley mlo-5 and mlo-1 and the respective parental cultivars, cv. Pallas and Haisa. Data are based on $n=5$ independent replicates (C and D); at least 100 interactions per leaf and three leaves were scored for each replicate. Letters denote statistical groups at $P<0.05$ according to GLM-Poisson testing. posable elements are equally distributed throughout these genomes, which are further characterized by extensive copy number variation of effector genes and the loss of some conserved ascomycete genes $(13,15)$. In particular, long interspersed nuclear element (LINE) and long terminal repeat (LTR) retrotransposons are highly abundant, and these elements exhibit very low sequence divergence, suggesting that recent transposon bursts shaped the genome of B. graminis (13).

At least 900 species of powdery mildew fungi (Ascomycota, Erysiphaceae) infect $>10,000$ plant species worldwide (16), including crops, trees, and herbs (17). The pathogen causes significant yield losses if not held in check by fungicides, affecting grain yield and quality (18). Even though powdery mildews apparently occur as homogenous strains due to their dominating asexual mode of propagation, they can have a complex population structure with many different haplotypes present within a supposedly clonal isolate (19).

The loss-of-function mutation of Mildew resistance Locus $O$ $(M L O)$ gene(s) confers highly effective and durable broadspectrum resistance against powdery mildew in many plant species (20). Pathogenesis is terminated prior to fungal host cell entry on mlo mutants, which have been used widely in European barley agriculture since the late 1970s (21). $M L O$ genes encode seven-transmembrane domain proteins $(22,23)$ with a cytosolic calmodulin-binding domain in the carboxy-terminus (24) and yet unresolved biochemical function (20). Genetic suppressors of mlo-based resistance cause partial susceptibility to powdery mildew. These include the
Required for mlo-specified resistance (Ror) genes in barley $(25,26)$, as well as PENETRATION (PEN) genes in Arabidopsis thaliana, which are major components of prepenetration resistance to powdery mildew (26-28). In addition, abiotic stress conditions can result in a temporary breakdown of $m l o$-based resistance $(29,30)$. The Japanese $B g h$ isolate RACE1 is the only known natural case with partial virulence on barley mlo mutant plants $(31,32)$. The mlo virulence phenotype in $B g h$ depends on a small number of unidentified genes $(33,34)$, but the underlying mechanism remains elusive.

To close this gap in knowledge, we here deployed real-time evolution experiments to select a set of $m l o$-virulent $B g h$ isolates for detailed molecular analysis. We identified a distinctive pattern of few convergent mutational events in the three identified isolates, resulting in an altered transcriptional program during fungal pathogenesis on barley mlo mutant plants. Our data suggest that mutations in a gene coding for an ortholog of the Aspergillus transcriptional regulator medA cause altered conidiospore morphology. Enhanced Bgh virulence on mlo mutants seems to be correlated with a fitness cost in the form of lowered virulence on barley wild-type plants, which may explain why the mlo-virulent phenotype does not prevail under agricultural conditions. Collectively, our findings provide an example of how few mutations in the genome of a phytopathogen can cause a drastic change in its virulence spectrum, enabling its rapid adaptation to new host environments. 


\section{Results}

Selection of three partially mlo-virulent $B g h$ isolates by experimental evolution. To study the rapid evolution of $B g h$ experimentally, we selected for $m l o$-virulent $B g h$ isolates derived from the mlo-avirulent parental strain $B g h \mathrm{~K} 1$. For 15 asexual generations, occasionally occurring $B g h \mathrm{~K} 1$ colonies on otherwise highly resistant barley mlo mutant plants were recovered, fungal biomass proliferated on the susceptible (Mlo genotype) cultivar (cv.) Ingrid, and then conidia re-inoculated on mlo plants, as described before (35). Subsequently, the resulting $B g h$ isolates were cultivated on barley mlo mutant plants only, yielding the three independent strains Supervirulent K1 (SK1), SK2, and SK3. These isolates showed stable yet partial mlo virulence with visible sporulation and a $15-25 \%$ host cell entry rate on barley mlo-3 mutant plants (Figure 1A and 1B). Bgh SK1 exhibited a similar level of virulence on a range of near-isogenic mlo lines with various mutational defects in Mlo (36), indicating that in contrast to Bgh RACE1 (37) the enhanced virulence of this strain is independent of the host mlo allele (Figure 1C and Supplementary Figure 1). We found comparable host cell entry levels on two mlo mutants in different barley lines, Pallas mlo-5 (approx. 15\%) and Haisa mlo-1 (approx. 20\%; Figure 1D), demonstrating that the $B g h$ SK1 virulence phenotype is also independent of the host genetic background. We nevertheless noticed a slight but statistically significant reduction of $B g h$ SK1 host cell entry rates compared to $B g h$ $\mathrm{K} 1$ on all wild-type (Mlo) genotypes tested (cv. Ingrid, Pallas and Haisa; Figure 1B and 1C), suggesting a reduction in pathogenic fitness in the $m l o$-virulent fungal isolate (see also below).

\section{Enhanced virulence of Bgh SK1 is restricted to $\mathrm{mlo}$ mutants in barley and Arabidopsis thaliana. To assess} whether $B g h$ SK1 has a generally altered virulence spectrum, we inoculated various host (barley) and nonhost (A. thaliana) genotypes with conidia of this isolate and assessed the infection success. On barley mlo rorl and mlo ror 2 double mutants, which have partially compromised mlo resistance due to second-site mutations in the genes Rorl and Ror2 (25), the $m l o$-virulent isolate Bgh SK1 showed elevated entry rates compared to mlo single mutant plants, indicative of an additive effect of the host ror mutations and the presumed genomic alterations in the fungal pathogen. Further, $B g h$ SK1 exhibited increased host cell entry upon treatment with the cytoskeleton-disrupting agent alloxan (38) (Supplementary Figure 2), indicating that its partial mlo virulence does not rely on interference with cytoskeleton reorganization and associated secretory pathways. On barley lines carrying Mildew resistance locus A (Mla) alleles conferring isolate-specific immunity with different levels of effectiveness against $B g h \mathrm{~K} 1(32,39), B g h$ SK1 showed reduced entry success, but also on the near-isogenic control cultivars lacking the respective Mla genes (Supplementary Figure 3), suggesting that the isolate is incapable of overcoming racespecific resistance. $B g h$ SK1 was further unable to colonize eight wheat cultivars and exhibited entry success levels com- parable to $B g h \mathrm{~K} 1$, except on three cultivars where we observed a slight increase (Supplementary Figure $4 \mathrm{~A}$ and B). Notably, Bgh SK1 had significantly reduced penetration success on the A. thaliana mutants pen2 pad4 sag101 and pen1, which are partially defective in resistance to the non-adapted $B g h$ pathogen $(26,27)$, but increased entry success on the A. thaliana mlo2 single mutant and the mlo2 mlo6 mlo12 pen 1 pen 2 quintuple mutant. Bgh SK1 even succeeded with occasional entry on the otherwise extremely resistant $m l o 2$ mlo6 mlo12 triple mutant, providing an additional link to $m l o$ virulence also in the Bgh nonhost species A. thaliana (Supplementary Figure 4C).

Bgh SK1 has an altered transcriptional profile during haustorium formation. To identify genes contributing to $m l o$ virulence in $B g h$ SK1 compared to $B g h \mathrm{~K} 1$ we performed whole transcriptome shotgun sequencing (RNA-seq) at 6 hours post inoculation (hpi; appressorium formation) and 18 hpi (haustorium establishment; Supplementary Table 1) using RNA extracted from inoculated barley leaf epidermal strips. The expression profiles of the host, representing the majority of the RNA-seq reads ( $>90 \%)$, did not vary significantly between the barley epidermal samples inoculated with the two $B g h$ isolates according to principal component analysis (PCA; Figure 2A, Supplementary Figure 5, and Supplementary Tables 2 and 3). PCA revealed a clear separation of the host and pathogen responses between 6 hpi and $18 \mathrm{hpi}$. However, there were no differentially expressed (DE) host genes at $6 \mathrm{hpi}$ and only seven DE genes at $18 \mathrm{hpi}$ (log fold change $>11 \mid, P_{\text {adj }}<0.05$; Supplementary Table 4$)$. Between 282,167 (3.5\%) and 1,472,273 (9.9\%) RNA-seq read pairs mapped to the manually annotated $B g h$ reference genome DH14 v4 (13) (Supplementary Table 1). While we did not identify DE genes at $6 \mathrm{hpi}, 121$ genes were significantly $\left(P_{\text {adj }}\right.$ $<0.05$; log fold change $>$ 11I) up-regulated and two genes down-regulated in Bgh SK1 at 18 hpi compared to Bgh K1 (Figure 2, Supplementary Figure 5, and Supplementary Tables 5 and 6). Among the 121 up-regulated genes, 93 (76.8\%) code for proteins that harbor a canonical secretion signal (mostly putative effectors; Supplementary Table 7). The two down-regulated genes were $B L G H \_02703$ and $B L G H \_06013$ (see below). We validated the expression profiles of six upregulated and the two down-regulated genes by quantitative reverse transcription polymerase chain reaction (qRT-PCR) and found that most of these genes behave similarly in $B g h$ strains SK2 and SK3, pointing to a common transcriptomic signature during pathogenesis in the three mlo-virulent isolates (Figure 2D, Supplementary Figure 6).

Three genes are affected by genomic events in the mlo-virulent $B g h$ isolates. Next, we explored whether genomic alterations occur between the three $B g h$ SK isolates and their parental meta-population (Bgh K1) using wholegenome shotgun sequencing (Supplementary Table 8). We queried these genomes after at least 50 asexual generations when the mlo virulence phenotype stabilized, since we expect purifying selection will have favored adaptive mutations to dominate within the populations at this time. Com- 
bioRxiv preprint doi: https://doi.org/10.1101/2021.12.09.471931; this version posted December 9, 2021. The copyright holder for this preprint (which was not certified by peer review) is the author/funder, who has granted bioRxiv a license to display the preprint in perpetuity. It is made available under aCC-BY-NC 4.0 International license.

A

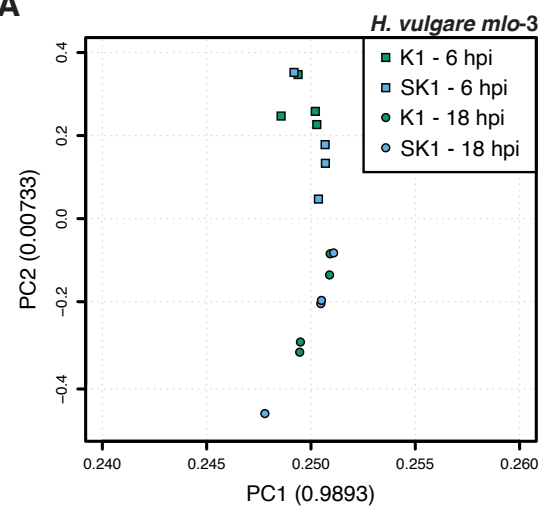

B

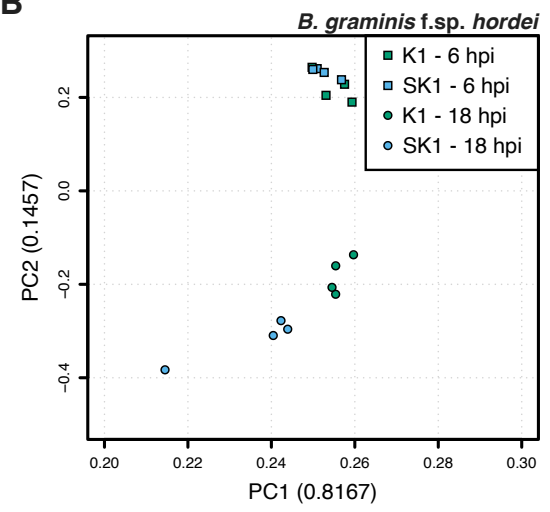

C

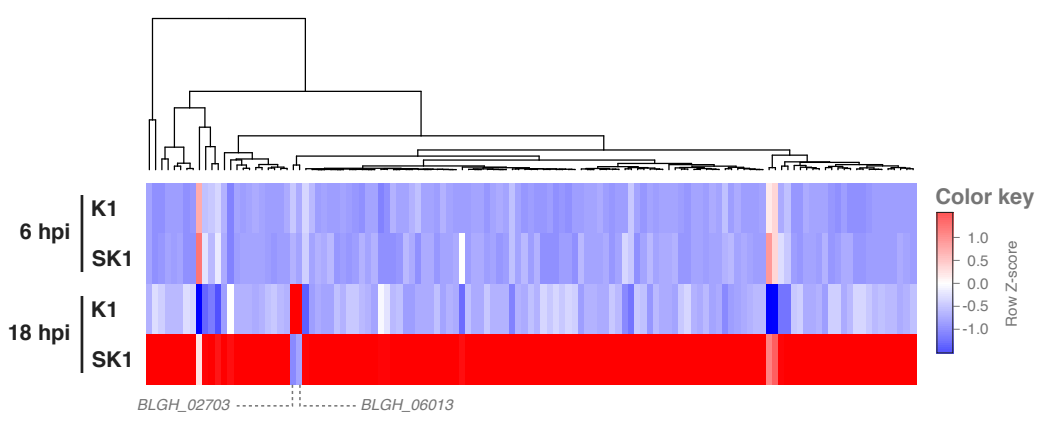

D

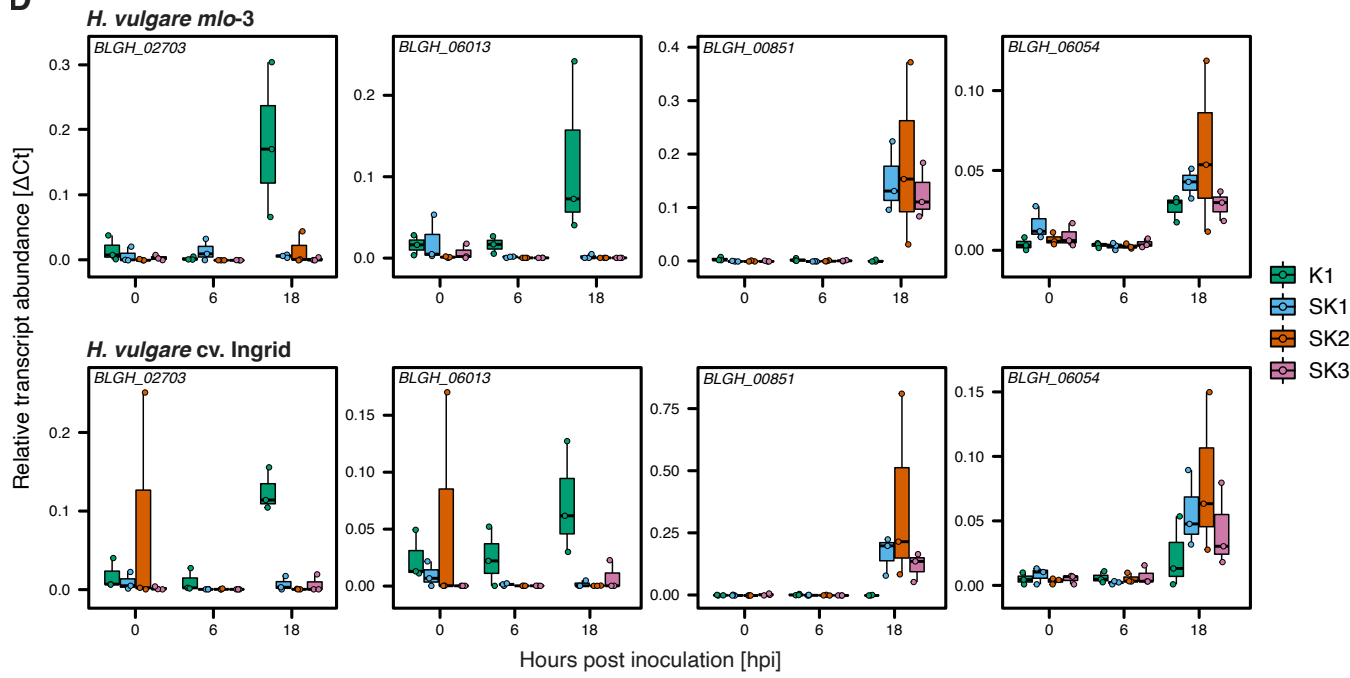

Fig. 2. A distinct transcriptomic pattern is associated with $\mathbf{m l o}$ virulence of $\boldsymbol{B g h}$ isolate SK1. We conducted RNA-seq of epidermal samples collected from barley BCl mlo-3 inoculated with Bgh K1 and SK1, respectively, at 6 hpi and $18 \mathrm{hpi}$, each with $n=4$ independent replicates. (A) Principal component (PC) analysis of gene expression in barley mlo-3 in the 18 samples accounting for the four conditions. Green, K1; blue, SK1; squares, 6 hpi; circles, 18 hpi. Numbers in brackets indicate the ratio of data explained by the principal component. (B) PCA of gene expression in Bgh K1 and Bgh SK1 at 6 hpi and 18 hpi on barley mlo-3. (C) Differential expression analysis revealed 121 up-regulated and 2 down-regulated genes in Bgh SK1 at 18 hpi on barley mlo-3 (Supplementary Figure 5, Supplementary Table 6). The heatmap shows the normalized relative expression (expressed as Row Z score) of these 123 genes in the two isolates at 6 and 18 hpi according to the color-coded scale on the right. (D) Data of qRT-PCR analysis for BLGH_02703, BLGH_06013, and six up-regulated genes (see Supplementary Figure 6 for full set) according to DE analysis for the isolates Bgh K1 (green), SK1 (blue), SK2 (orange), and SK3 (purple) after inoculation of barley mlo-3 or cv. Ingrid. The x-axis shows the time-point after inoculation (0, 6 , and $18 \mathrm{hpi}$ ), the y-axis displays relative transcript abundance calculated by $\Delta \mathrm{Ct}$ analysis. Data shown are based on $n=3$ biological replicates with 3 technical replicates each. 
bioRxiv preprint doi: https://doi.org/10.1101/2021.12.09.471931; this version posted December 9, 2021. The copyright holder for this preprint (which was not certified by peer review) is the author/funder, who has granted bioRxiv a license to display the preprint in perpetuity. It is made available under aCC-BY-NC 4.0 International license.

A

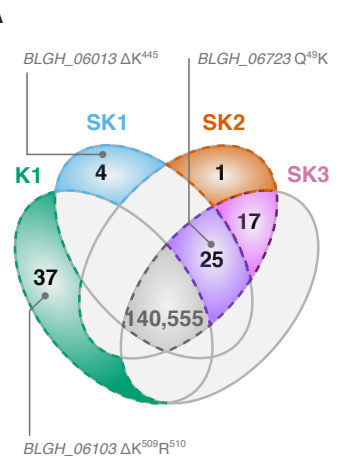

C

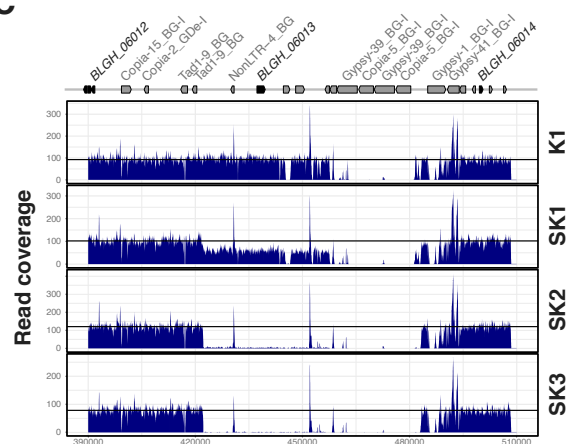

Bgh DH14 scaffold_34

E

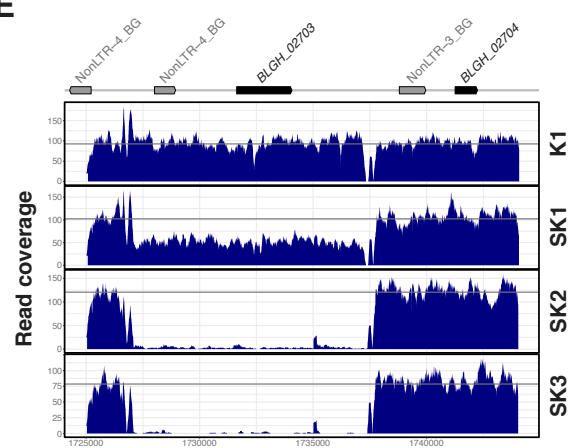

Bgh DH14 scaffold_23
B

Bgh

isolate SK1

Bgh $\bar{x}$
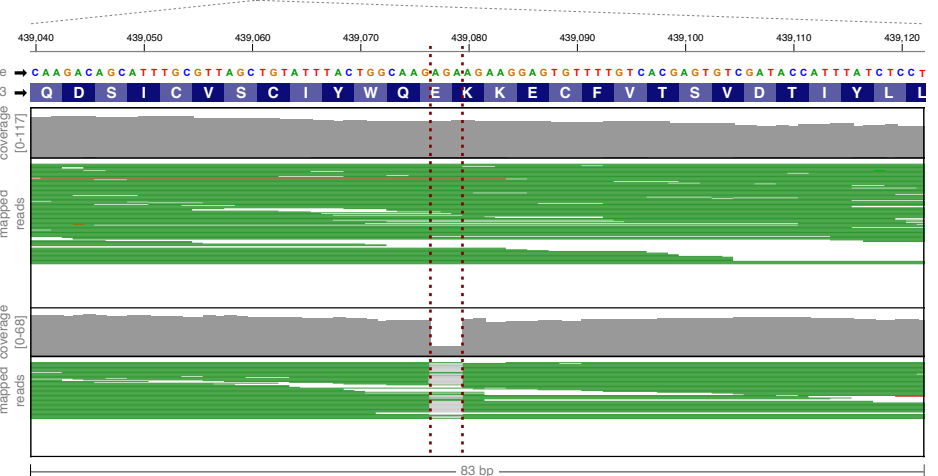

D

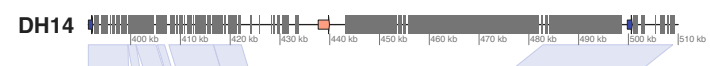

SK1
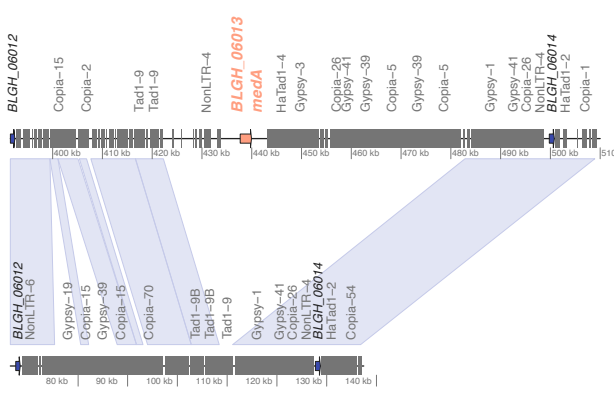

DH14: scaffold_34

SK1: sk1_contig_609

$\mathbf{F}$

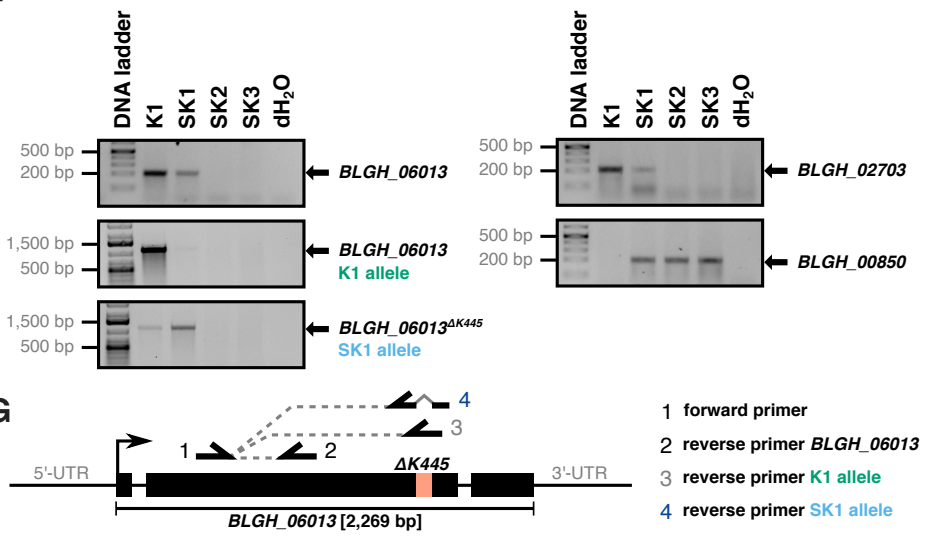

Fig. 3. Loss of genes $B L G H \_06013$ and $B L G H \_02703$ in $\boldsymbol{m l o}$-virulent $\boldsymbol{B g} \boldsymbol{h}$ isolates. We performed high-throughput whole-genome DNA sequencing with the isolates Bgh K1, SK1, SK2, and SK3. (A) Venn diagram summarizing single nucleotide variants (SNVs) occurring in Bgh K1, SK1, SK2, and SK3 relative to the reference genome of $B g h \mathrm{DH} 14$ v4. All variants were confirmed by manual inspection, except the SNVs common in all four isolates (grey). SNVs affecting coding sequences are indicated. (B) SNVs were detected with Freebayes using an optimized pipeline and visualized using the IGV browser. The red lines highlight a variation (3 bp deletion) in Bgh SK1 compared to K1. White bar, scaffold_34 of the Bgh DH14 reference assembly; below, the nucleotide and amino acid sequence of BLGH_06013 are shown. Mapping coverage is shown in grey, individual mapped reads are displayed in green, gaps in light grey. (C) Mapping coverage of Bgh DH14 scaffold_34:390,000...510,000 of Bgh K1, SK1, SK2, and SK3, including the locus of BLGH_06013. The x-axis shows the position on the scaffold, the y-axis read coverage, and transposable elements are indicated at the top. The black line shows the average coverage for the respective isolate, site-specific coverage is displayed in dark blue. (D) Local synteny plot of scaffold_34:390,000...510,000 (BLGH_06013 locus in orange). Genes are indicated by blue arrows and transposable elements by grey blocks. Bgh DH14 scaffold_34 was assembled in Bgh SK1 (sk1_contig_609) using nanopore MinION sequencing. (E) Mapping coverage of Bgh DH14 scaffold_23:1,725,000...1,750,000 of Bgh K1, SK1, SK2, and SK3, including the locus of BLGH_02703. Displayed as in (C). (F) Genotyping PCRs for BLGH_02703 and BLGH_06013 alleles using genomic DNA of Bgh K1, SK1, SK2, and SK3, respectively. Gene $B L G H \_00850$ served as a positive control for PCR amplification. DNA Ladder, 1 kb plus (Invitrogen-Thermo Fisher, Waltham, MA, USA). (G) Primer locations for genotyping of $B L G H \_06013$. Oligonucleotides are listed in Supplementary Table 12. 
bioRxiv preprint doi: https://doi.org/10.1101/2021.12.09.471931; this version posted December 9, 2021. The copyright holder for this preprint (which was not certified by peer review) is the author/funder, who has granted bioRxiv a license to display the preprint in perpetuity. It is made available under aCC-BY-NC 4.0 International license.

Table 1. Mutational events detected in Bgh SK1, SK2, and SK3.

\begin{tabular}{|c|c|c|c|c|c|}
\hline Gene & BLGH_06013 & BLGH_06723 & BLGH_02703 & $\begin{array}{l}\text { BLGH_05230 } \\
\text { BLGH_05231 } \\
\text { BLGH_05232 }\end{array}$ & BLGH_05233 \\
\hline Encoded protein & $\begin{array}{l}\text { MedA-like } \\
\text { transcriptional } \\
\text { regulator }\end{array}$ & $\begin{array}{l}\text { E3 ubiquitin } \\
\text { ligase }\end{array}$ & $\begin{array}{l}\text { Unknown protein, } \\
\text { Blumeria-specific }\end{array}$ & $\begin{array}{l}\text { Nuclear transport factor } \\
\text { (karyopherin) / } \\
\text { aminopeptidase / } \\
\text { glutathione peroxidase }\end{array}$ & $\begin{array}{l}\text { Sgk2-like serine- } \\
\text { threonine protein } \\
\text { kinase }\end{array}$ \\
\hline \multicolumn{6}{|l|}{$B g h$ isolate } \\
\hline $\mathrm{K} 1$ & n.v. ${ }^{\mathrm{a}}$ & n.v. & n.v. & $2 x$ coverage & $3 x$ coverage \\
\hline SK1 & $\begin{array}{l}\text { Absent (partially) } \\
\Delta \mathrm{K}^{445} \text { (partially) }\end{array}$ & $\mathrm{Q}^{49} \mathrm{~K}$ & Absent (partially) & $2 \mathrm{x}$ coverage & $3 x$ coverage \\
\hline SK2 & Absent & $\mathrm{Q}^{49} \mathrm{~K}$ & Absent & $1 \mathrm{x}$ coverage & $2 x$ coverage \\
\hline SK3 & Absent & $\mathrm{Q}^{49} \mathrm{~K}$ & Absent & 1x coverage & $2 x$ coverage \\
\hline
\end{tabular}

${ }^{a}$ n.v., no variation compared to the reference $B g h$ isolate DH14 v4 (13).

pared to the near-chromosome level reference genome sequence of $B g h$ DH14, isolates K1 and SK1, SK2, and SK3 shared 140,639 single nucleotide variants (SNVs), 2,137 of which were predicted to vary between the isolates. We manually confirmed 84 unambiguous polymorphisms of which 81 were intergenic and three affected genes (Figure 3A, Table 1, and Supplementary Table 9). SK2 and SK3 only differed in one intergenic SNV, implying that the two isolates are genetically redundant. The other variations include an SNV in $B L G H \_06723$ (encoding a putative conserved RBR-family E3 ubiquitin ligase), causing the change of glutamine-49 to lysine in all three mlo-virulent isolates, and a three-base-pair deletion in gene BLGH_06013 in part of the SK1 population, causing the in-frame loss of lysine- 445 (BLGH_06013 ${ }^{\Delta \mathrm{K} 445}$; Figure 3B). BLGH_06013 encodes the orthologue of Aspergillus fumigatus Af293 medA (medusa; BLASTP query cover $75 \%$, identity $43.7 \%$, E value $3 \mathrm{E}-112$; GenBank accession XP_755658.1; Supplementary Figure 8). The above-mentioned lysine-445 (lost in BLGH_06013 in part of the SK1 population) appears to represent a positionally conserved amino acid in nearly all medA sequences analyzed (Supplementary Figure 9). We then calculated the average read coverage of all genes from the reference annotation (13), revealing two gene losses and two instances of copy number variation in the SK isolates (Supplementary Figure 7). One loss affected BLGH_06013 and was due to deletion of an almost 40-kb region compared to $B g h \mathrm{~K} 1$ at scaffold_34 (422,240-451,834). While this region was completely absent in Bgh SK2 and SK3, SK1 exhibited about $50 \%$ loss of coverage, indicating a deletion present in part of the population (Figure 3C). We reassembled scaffold_34 of SK1 using nanopore MinION sequencing (Supplementary Table 10), which confirmed the deletion in a subset of the population with this long-read technology and revealed the apparent de novo insertion of a Tadl-9 retrotransposon at this site, replacing the 40-kb region (Figure 3D). The second gene loss concerned BLGH_02703 and was due to an 8-kb deletion in scaffold_23:1,727,078-1,735,005, where the reads again exhibited reduced (approx. 50\%) coverage in SK1 and complete absence of the locus in SK2 and SK3 (Figure 3E). BLGH_O2703 has no similarity to known proteins in the NCBI database except in the closely related wheat pow- dery mildew pathogen, B. graminis f.sp. tritici (EPQ63962; BLASTP query cover $92 \%$, E value $2 \mathrm{e}-154,68.3 \%$ sequence identity), and otherwise has weak similarity to atrophin$1, \mathrm{~K}^{+}$-dependent $\mathrm{Na}^{+} / \mathrm{Ca}^{+}$exchanger, and the alpha subunit of transcription initiation factor IIF (Supplementary Table 11). Both regions showing deletions in the SK isolates (in scaffolds 23 and 34) were flanked by long terminal repeat (LTR)-type transposable elements such as Tad1, Gypsy, Copia, and Non-LTR4 (Figure 3C and 3E). Partial absence of BLGH_02703 and BLGH_06013 within the Bgh SK1 population likely accounts for the reduced transcript accumulation of these two genes seen in RNA-seq analysis at $18 \mathrm{hpi}$ (see above). We did not find these three polymorphisms in the naturally $m l o$-virulent RACE1 isolate, suggesting that its virulence is mechanistically different from $B g h$ SK 1 and SK2/3. The copy number variations we detected were limited to two loci (Supplementary Figure 7 and 10). Scaffold_27:312,420348,900 encompasses BLGH_05230, BLGH_05231, and BLGH_05232, coding for a karyopherin nuclear transport factor, an aminopeptidase, and a glutathione peroxidase, respectively. The region exhibited approx. 2-fold coverage by sequence reads of isolates K1 and SK1 compared to isolates SK2 and SK3, whose sequence reads showed no elevated coverage for these three genes. Likewise, sequence coverage indicated that the neighboring gene BLGH_05233, encoding a Sgk2-like serine-threonine kinase, was represented by two copies in isolates $B g h$ SK2 and SK3 instead of three copies in isolates $B g h \mathrm{~K} 1$ and SK1. Scaffold_8:1,787,835$1,794,235$, containing BLGH_00850, whose encoded protein is $36.5 \%$ similar to the protein encoded by the adjacent gene BLGH_00851 (CSEP0327) and thus possibly a diverged copy thereof, was recently (probably in 2018) lost in our locally propagated $B g h \mathrm{~K} 1$ population $\left(B g h \mathrm{~K} 1_{\text {Aachen }}\right)$ but not in the original $B g h \mathrm{~K} 1$ population $\left(B g h \mathrm{~K} 1_{\text {Cologne }}\right)$ and also not in the SK descendants derived from $B g h \mathrm{~K} 1$ (see below; Supplementary Figure 10A and 11). We confirmed the presence-absence polymorphisms of $B L G H \_02703$ and BLGH_06013 by genotyping PCR and the $\mathrm{C}^{222} \mathrm{~A}$ nucleotide exchange in BLGH_06723 by Sanger sequencing of the PCR products (Figure 3F and Supplementary Figure 12). We summarized all genomic alterations detected in the three $B g h$ SK isolates in Table 1. 
A

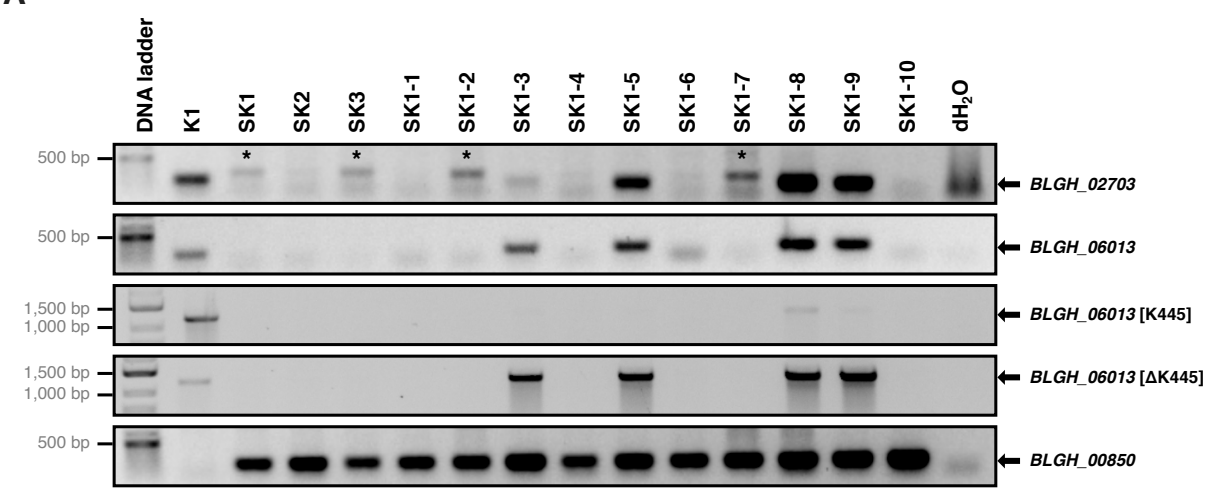

B

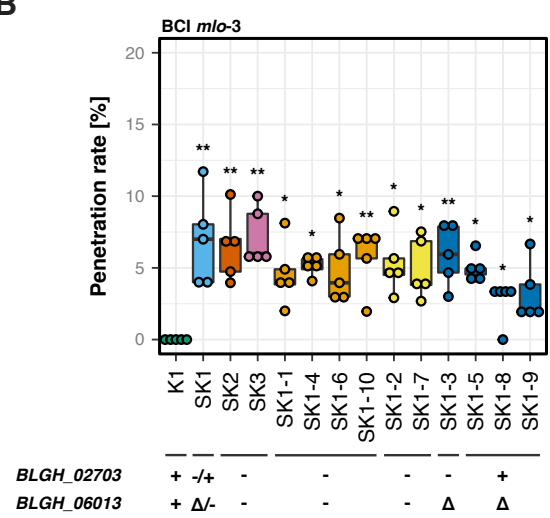

C

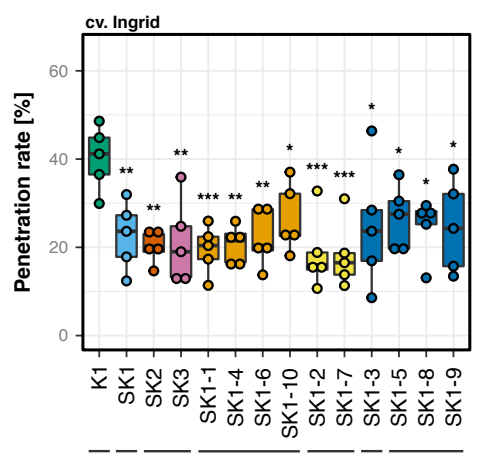

BLGH_02703 BLGH_06013

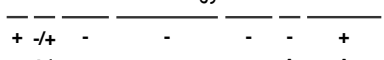

Fig. 4. Loss of $B L G H 02703$ is dispensable for mlo virulence in Bgh SK1. Using the Bgh SK1 meta-population, we captured several defined mutant genotypes and combinations thereof as single spore isolates. (A) Genotyping PCR for BLGH_02703 and BLGH_06013 with three different primer pairs as indicated in Figure $3 G$ on genomic DNA isolated from various $\mathrm{Bgh}$ isolates. Asterisks indicate a sporadically occurring non-specific PCR product in case of the BLGH_02703 PCR; since the origin of these bands is unclear, lines with these bands are indicated in yellow in the boxplots in panels (B) and (C). Gene BLGH_00850 served as a positive control for PCR amplification. (B and $\mathbf{C}$ ) Penetration success [\%] of conidia from Bgh isolates K1 (green), SK1 (blue), SK2 (orange), SK3 (purple), and the ten isolates (light orange, yellow, and blue) analyzed in (A) on barley $\mathrm{BCl}$ mlo-3 (B) and cv. Ingrid (Mlo) (C). Genotypes are colorcoded as indicated below the panels ( $\Delta$ indicates BLGH $06013^{\Delta \mathrm{K} 445}$ ). Data are based on $n=5$ independent replicates. At least 100 interactions per leaf and three leaves were scored for each replicate. Asterisks indicate statistically significant differences to $\mathrm{K} 1$ at *, $P<0.05 ;{ }^{* *}, P<0.01 ;{ }^{* *}, P<0.001$, according to GLM-Poisson testing.
Loss of BLGH_02703 is dispensable for mlo virulence of $\boldsymbol{B g h}$ SK1. We next aimed to address whether the mlo virulence phenotype depends on the loss of the genes BLGH_02703 and/or BLGH_06013, which are partially absent or mutated in the Bgh SK1 population (Figure 3, Table 1). Given the lack of reliable genetic tools for obligate biotrophic plant pathogens including powdery mildews, we took advantage of the non-homogenous SK1 population to isolate single spore-derived and PCR-validated $\mathrm{Bgh}$ genotypes. We succeeded in separating individual colonies that either carry or lack BLGH_02703 in combination with either the $B L G H \_06013$ deletion or the $B L G H \_06013^{\Delta K 445}$ variant (three different combinations; Figure 4A). The entry success of these genotypes on mlo mutant leaves ranged from $5-12 \%$, and there was no statistically significant difference in this respect between these isolates (Figure 4B). By contrast, reminiscent of the original SK1 isolate (Figure 1D), SK2 and SK3 as well as all SK1-derived genotypes showed reduced entry access on barley wild-type (Mlo genotype) leaves (Figure 4C). Transient silencing of BLGH_O2703 and $B L G H \_06013$, separately or in combination, by particle bombardment-mediated host-induced gene silencing (40) did not confer virulence to $B g h \mathrm{~K} 1$ on barley mlo-3 leaves (Supplementary Figure 13). Taken together, this data indicates that the loss of BLGH_02703 is not required for Bgh to acquire mlo virulence.
Loss of BLGH_06013 affects conidia Bgh morphology. The transcription factor medA is required for conidia formation in the ascomycete Aspergillus fumigatus, as A. fumigatus medA mutants display aberrations in conidia number and shape $(41,42)$. We observed that while $B g h$ K1 exhibited uniform oval-shaped conidiospores, the mlovirulent isolates SK1, SK2, and SK3 showed the presence of markedly elongated ellipse-shaped conidiospores (Figure $5 \mathrm{~A})$. We, therefore, assessed essential conidia size parameters (length, width, length/width ratio, area, perimeter) of the SK isolates in comparison to Bgh $\mathrm{K} 1$. All tested mlovirulent genotypes (SK1, SK2, SK3, and the mutant combinations described above) had significantly increased conidia length (median 32-36 $\mu \mathrm{m}$ ) compared to the parental isolate $B g h \mathrm{~K} 1$ (median $23 \mu \mathrm{m}$; Figure 5B). The same applied to the conidia length/width ratio (approx. 3.0 vs. 2.1) and perimeter (approx. $82 \mu \mathrm{m}$ vs. $56 \mu \mathrm{m}$ ), and, in tendency, to conidia area (approx. $213 \mu \mathrm{m}^{2}$ vs. $160 \mu \mathrm{m}^{2}$ ), while conidia width of the SK isolates was indistinguishable from $B g h$ K1 conidia (both approx. $11 \mu \mathrm{m}$; Supplementary Figure 14). These findings suggest that $B L G H \_06013$ (medA) is involved in the determination of conidia shape in $B g h$, analogous to its role in A. fumigatus. Similar to the mlo virulence phenotype (Figure 4), the aberrant conidia shape phenotype is independent of BLGH_02703 and occurred with both the null allele of $B L G H \_06013$ and the single amino acid deletion variant $B L G H \_06013^{\Delta \mathrm{K} 445}$ (Figure 5B). We hypothesized that the aberrant conidia shape might affect the fitness of $B g h$ SK iso- 
bioRxiv preprint doi: https://doi.org/10.1101/2021.12.09.471931; this version posted December 9, 2021. The copyright holder for this preprint (which was not certified by peer review) is the author/funder, who has granted bioRxiv a license to display the preprint in perpetuity. It is made available under aCC-BY-NC 4.0 International license.

\section{A}
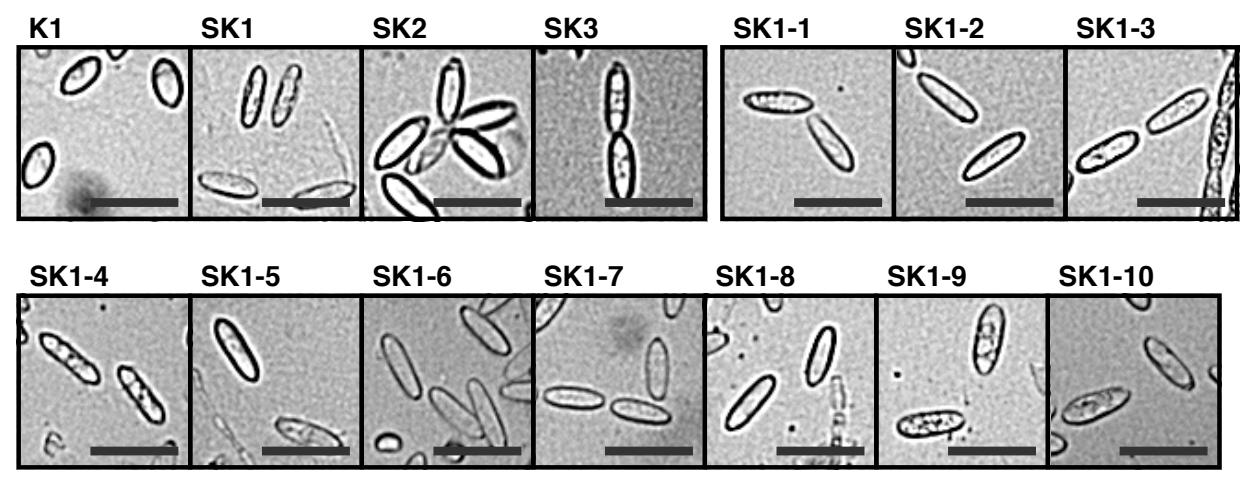

B

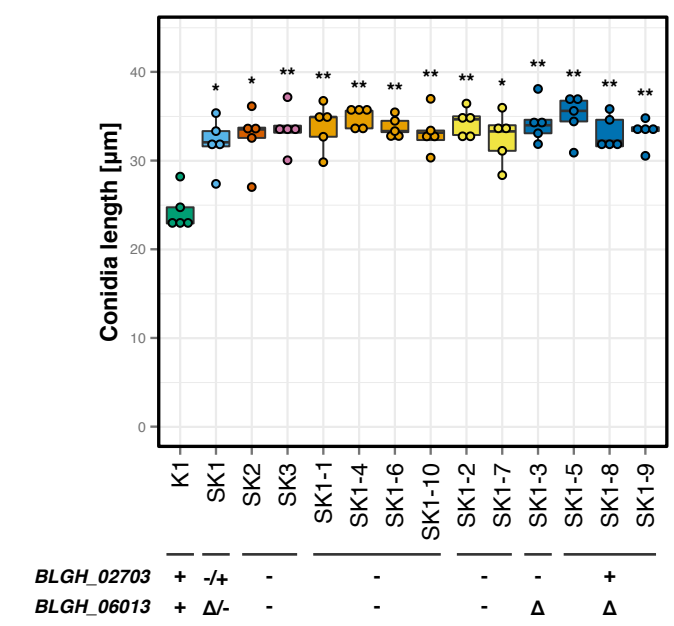

C

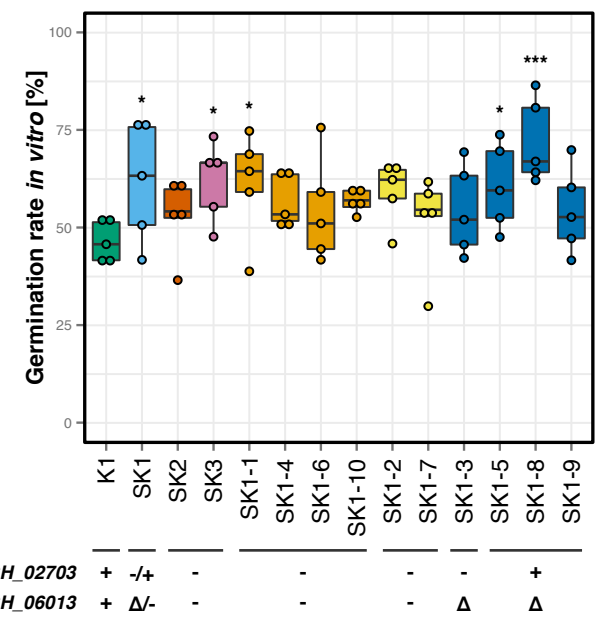

$\mathbf{E}$

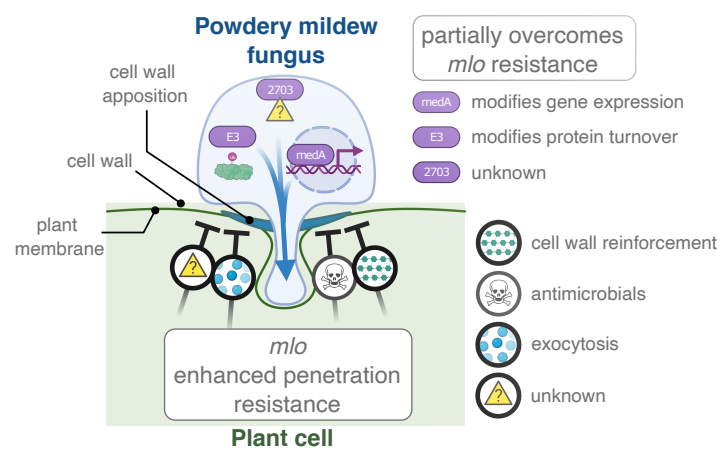

$\begin{array}{llllllllllllllll}\text { BLGH_02703 } & +-1+ & - & - & - & - & + \\ \text { BLGH_06013 } & +\Delta /- & - & - & - & \Delta & \Delta\end{array}$
Plant cell

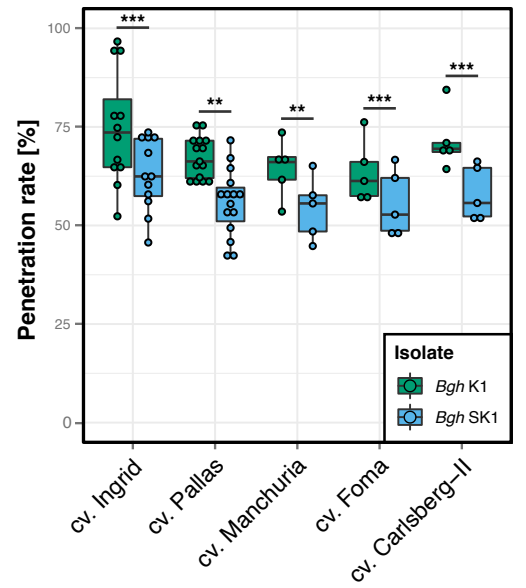

D

Fig. 5. The loss of BLGH_06013 affects conidiospore morphology. (A) Representative micrographs of conidia (brightfield); scale bar: $50 \mu \mathrm{m}$. (B) Length of conidia [ $\mu \mathrm{m}]$ for $B g h K 1$, SK1, SK2, SK3, and ten isolates derived from the SK1 meta-population. Genotypes are color-coded as indicated below the panels $\left(\Delta\right.$ indicates $\left.B L G H \_06013^{\Delta K 445}\right)$. Statistical analysis was performed via GLM (Poisson); $n=5$ independent replicates. ${ }^{*}, P<0.05 ;{ }^{* *}, P<0.01 ;{ }^{* *}, P<0.001$. (C) Conidia were inoculated on agar plates and the germination rate (appearance of primary germ tubes) in \% determined after 6 h. $n=5$ independent replicates. Genotypes are color-coded as indicated below the panels ( $\Delta$ indicates BLGH_06013 ${ }^{\Delta 445}$ ). ${ }^{*}, P<0.05 ;{ }^{* *}, P<0.01 ;{ }^{* * *}, P<0.001$. (D) Penetration success [\%] of conidia from Bgh K1 (green) and SK1 (blue) on barley cultivars (Mlo genotype) Ingrid $(n=12)$, Pallas $(n=15)$, Manchuria, Foma, and Carlsberg-II $(n=5$ independent replicates each). Statistical analysis was performed comparing SK1 with $\mathrm{K} 1$ on the respective cultivar using GLM (Poisson); ${ }^{*}, P<0.05 ;{ }^{* *}, P<0.01 ;{ }^{* * *}, P<0.001$. (E) Model for partial mlo virulence in the barley powdery mildew pathogen. Multiple pathways contribute to mlo-based resistance against powdery mildew pathogens, including secretion-based resistance (e.g., the t-SNARE PEN1/Ror2 involved in defense-related vesicle fusion), cell wall reinforcements (e.g., callose appositions), and antimicrobial compounds (e.g., PEN2-mediated indole glucosinolates in A. thaliana). Our experiments demonstrated that $m l o$ virulence in $B g h$ SK1 is additive to suppression of resistance by loss of known pathways, suggesting a different mechanism that leads to successful infection. We identified three genes to be associated with the mlo virulence in Bgh SK1 and SK2/3, the E3 ubiquitin ligase BLGH_06723, the transcriptional regulator BLGH_06013, and a third protein of unknown function (BLGH_02703). We postulate that these three genes alter the infection program of Bgh SK1 and SK2/3 to collectively enable infection of m/o-resistant barley. Purple ovals symbolize the three proteins found to be lacking/mutated in the three Bgh SK1 isolates. 
lates. We allowed the conidia of $B g h \mathrm{~K} 1, \mathrm{SK} 1, \mathrm{SK} 2$, SK3, and the various genotypes to germinate on agar medium. Under these in vitro conditions, around $50-75 \%$ of conidia formed germ tubes. The majority of the SK isolates displayed normal or slightly enhanced germination rates (approx. 50$70 \%$; Figure 5C), suggesting that germination and formation of the primary germ tube remained largely unaffected. Additionally, we analyzed a set of barley cultivars susceptible to $B g h \mathrm{~K} 1$ and carrying a functional Mlo allele to compare the entry success of the two isolates $B g h \mathrm{~K} 1$ and SK1. Intriguingly and consistent with our other experimental data (Figure 1D and Figure 4C), Bgh SK1 showed a significantly reduced entry success with a decrease of about $5-15 \%$ compared to $B g h \mathrm{~K} 1$ on these cultivars, suggesting a fitness penalty for $B g h$ SK1 (Figure 5D). To assess whether $B g h \mathrm{~K} 1$ would outcompete $B g h$ SK 1 as a consequence of this fitness penalty, we performed competition experiments. However, $B g h \mathrm{~K} 1 \mathrm{did}$ not outcompete $B g h$ SK1 in these settings, and mlo-virulent $B g h$ isolates did not lose their $m l o$ virulence after 12 generations of propagation on wild-type barley leaves (cv. Ingrid; Mlo genotype), i.e., in the absence of the selective pressure (Supplementary Figure 15).

\section{Discussion}

Experimental evolution can be a powerful tool to study genome evolution in plant-associated fungal microbes (43). Using this approach, we discovered a single amino acid exchange in one gene and the loss of two genes co-occurring in all three $B g h$ SK isolates (Table 1). This mutational spectrum correlates with the gain of virulence on otherwise highly powdery mildew-resistant barley mlo mutant plants, which confer a type of broad-spectrum resistance that mechanistically differs from isolate-specific immunity conferred by NLR proteins $(44,45)$. Other than mutations leading to the loss of NLR-mediated isolate-specific resistance, none of these genes code for effectors but rather a RBR-family E3 ubiquitin ligase (BLGH_06723), a medA-like transcriptional regulator (BLGH_O6013), and a protein of unknown function (BLGH_02703). The $\mathrm{Q}^{49} \mathrm{~K}$ substitution in $B L G H \_06723$ does not affect a conserved amino acid and is not located in an annotated functional domain of the protein (Supplementary Figure 16). We can, however, not exclude that this missense mutation leads to either a non-functional version or a gain-of-function variant, or, alternatively, affects the stability and accumulation levels of the protein. Our analyses based on the segregating SK1 population demonstrated that the lack of BLGH_O2703 is dispensable for both mlo virulence and the conidiospore morphology phenotype (Figure 4 and 5). Likewise, the copy number variation of genes $B L G H \_05230$, BLGH_05231,BLGH_05232, and BLGH_05233 is restricted to $B g h$ SK2 and SK3 (Table 1). These variations are thus unlikely to be causative for $m l o$ virulence. This leaves the $\mathrm{Q}^{49} \mathrm{~K}$ substitution in BLGH_06723 and/or the lack of BLGH_06013 as the most probable mutations conferring partial mlo virulence in the Bgh SK isolates. The lack of genetic tools for the obligate biotrophic powdery mildew pathogens at present prevents a more rigorous testing of the candidate genes, e.g., by targeted gene knock-outs or complementation analysis. It is intriguing that all three $B g h$ SK isolates share an almost identical set of adaptive mutations (Table 1). Similarly, previously isolated $B g h$ isolates depended on three unidentified genes that unequally contributed to $m l o$ virulence $(33,34)$. These experiments resulted in strains of three distinctive levels of virulence, suggesting at least three major adaptive mutations (46). This observation prompts the question whether these isolates represent independent mutational events, and whether these sequence variants might pre-exist as balanced polymorphisms within the $B g h \mathrm{~K} 1$ population or are independently and convergently acquired de novo events selected for during experimental evolution. Since isolate SK1 on the one hand and SK2/SK3 on the other hand were selected more than two years apart from each other, and differ in the mutational spectrum detected for $B L G H \_06013$ and the copy number variation of $B L G H \_05230, B L G H \_05231, B L G H \_05232$, and BLGH_05233 (Table 1), we can assume at least two independent and convergent sets of adaptive mutational events. By contrast, isolates SK2 and SK3 are near-identical and only differ by one validated SNV in an intergenic region, suggesting that these two isolates might have the same origin. $B g h$ isolates are non-homogenous and have a complex population structure, with many different haplotypes present within a supposedly clonal isolate (19). It may thus well be possible that a founder event for $m l o$ virulence (e.g., the $\mathrm{Q}^{49} \mathrm{~K}$ substitution in BLGH_06723) is present at low levels as a balanced polymorphism within the parental $B g h \mathrm{~K} 1$ population, which may give rise to sporadic colony formation on mlo plants. One or more additional events, such as the loss of functional BLGH_06013, might be required to stabilize virulence on mlo mutant plants. However, we found no evidence for the $B L G H \_06723 \mathrm{Q}^{49} \mathrm{~K}$ variant to be present in the $\mathrm{K} 1$ population, which could either mean that the variation does not pre-exist or occurs at a frequency below our detection limit.

Various processes could facilitate the rapid gain and loss of genes in $B g h$. Genome recombination due to mating can promote genetic diversity, which for example recently gave rise to the emergence of $B$. graminis f.sp. triticale by hybridization of wheat and rye powdery mildews (47). However, we isolated the mlo-virulent strains from asexuallyreproducing populations. Thus, the extensive repertoire of transposable elements (13) is the most likely driver of rapid genomic changes in the fungus. We noted that in the case of BLGH_06013 a Tadl-9 transposon appears to have replaced the locus containing this gene in SK1 (Figure 3D), suggesting that transposition of a Tadl element caused genome recombination at this site, consistent with the copy-paste mechanism of retroelements (48). However, the transposition itself would not explain the loss of a large genomic segment. While non-homologous end joining (NHEJ) is the dominant mechanism to repair double strand breaks in genomic DNA in haploid genomes $(49,50)$, it accounts predominantly for indels of $<20 \mathrm{bp}$. Microhomologies however can cause long-distance template switching due to replication fork collapse during cell division, which can frequently 
occur in repetitive and AT-rich regions $(51,52)$. The resulting DNA end intermediates can be stabilized and repaired by microhomology-mediated end joining (MMEJ), which in this case uses microhomologies from non-homologous templates and is therefore error-prone (53-55). Microhomologydriven replication-based DNA repair mechanisms such as MMEJ cause large-scale insertions, deletions, and copy number variation $(1,56,57)$. Since powdery mildew genomes are enriched with repetitive elements including retrotransposons that exhibit little sequence divergence $(13,58)$, microhomologies likely occur frequently and could give rise to extensive structural variation in the fungus. Typically, virulence genes encoding effectors, carbohydrate-processing enzymes (CAZymes), and toxins are often found in the vicinity of transposable elements, frequently embedded within transposon-rich genome compartments $(11,59,60)$. For example, population-wide screening of the gene content in the Septoria leaf blotch pathogen Zymoseptoria tritici identified 599 gene gains and 1,024 gene losses, which mainly occurred in subtelomeric regions and in proximity to transposable elements. The majority of these genes encode virulence factors, secreted proteins, and enzymes involved in the biosynthesis of secondary metabolites (8). Inaccurate microhomology-based repair of double strand breaks occurring in the transposon-rich and repetitive regions may be one major driver of copy number variation of effectors and other virulence factors.

Why do the mutational events observed in the Bgh SK isolates not occur naturally in barley powdery mildew populations in the field? This might be explained by the fact that the affected isolates show reduced infection success on susceptible (Mlo wild-type) barley genotypes (Figure 5D). Due to the adverse effects of this adaptation, such strains may not emerge in a non-selective environment where susceptible barley genotypes are available as hosts. It is conceivable that the rotation of mlo-resistant and non-resistant spring and winter varieties, respectively, as currently practiced by farmers in European agriculture (21), results in the absence of constant selection pressure, thereby preventing the occurrence of natural $m l o$-virulent strains so far. Given the rapidity with which mlo virulence appeared under our laboratory conditions, we caution against the permanent deployment of barley mlo mutants without rotation to prevent the appearance of mlo-virulent barley powdery mildew in agricultural settings.

\section{Methods}

Plant growth conditions. All plants were cultivated in SoMi513 soil (HAWITA). Healthy barley and wheat plants were grown under a long day cycle $(16 \mathrm{~h}$ light period at $23{ }^{\circ} \mathrm{C}, 8 \mathrm{~h}$ darkness at $20{ }^{\circ} \mathrm{C}$ ) with $60-65 \%$ relative humidity (RH) at a light intensity of $105-120 \mu \mathrm{mol} \mathrm{s}^{-1} \mathrm{~m}^{-2}$. Arabidopsis thaliana plants were cultivated under a short-day cycle $\left(8 \mathrm{~h}\right.$ light period at $22{ }^{\circ} \mathrm{C}, 16 \mathrm{~h}$ darkness at $\left.20^{\circ} \mathrm{C}\right)$, at $80-90 \% \mathrm{RH}$, and a light intensity of $100 \mu \mathrm{mol} \mathrm{s}^{-1} \mathrm{~m}^{-2}$. For powdery mildew infection assays, the plants were transferred to isolate-specific infection chambers with a long day cycle (12 h light at $20{ }^{\circ} \mathrm{C}$ and $12 \mathrm{~h}$ dark period at $19{ }^{\circ} \mathrm{C}$ ), ca. $60 \%$
RH and $100 \mu \mathrm{mol} \mathrm{s}^{-1} \mathrm{~m}^{-2}$.

Powdery mildew infection assays. One-week-old barley and wheat plants and four to five-week-old Arabidopsis plants (rosette size of $2-2.5 \mathrm{~cm}$ ) were used for powdery mildew infection assays. The powdery mildew conidiospores were blown onto the plants in an infection tower; spores were allowed to settle for 10-15 min. Inoculated plants were incubated in the respective $B g h$ infection chamber. The samples for penetration assays were bleached in $80 \%$ ethanol at $48 \mathrm{hpi}$. The leaves were submerged twice in Coomassie staining solution $(45 \% \mathrm{v} / \mathrm{v} \mathrm{MeOH}, 10 \% \mathrm{v} / \mathrm{v}$ acetic acid, $0.05 \%$ w/v Coomassie blue R 250; Carl Roth, Karlsruhe, Germany) for $15-20 \mathrm{~s}$, and then mounted on a glass slide with $50 \%$ glycerol. The samples were evaluated by bright field microscopy. Leaves from four to five plants/genotype were scored for penetration success with 100-200 interaction sites per leaf. Penetration success is expressed as the percentage of spores forming secondary hyphae upon interaction over spores forming an appressorium only.

For the Bgh-Arabidopsis interaction assays, the leaves were stored in Aniline blue staining solution $\left(150 \mathrm{mM} \mathrm{K}_{2} \mathrm{HPO}_{4}\right.$, $0.01 \%$ w/v Aniline blue; Sigma-Aldrich, Munich, Germany) in the dark overnight to stain callose, before Coomassie staining. These samples were analyzed by fluorescence microscopy with illumination by a UV lamp (bandpass $327-427 \mathrm{~nm}$ ) and an emission filter for Aniline/DAPI at $417-477 \mathrm{~nm}$.

Analysis of conidia shape. Conidia were collected from the surface of susceptible barley leaves at $7 \mathrm{dpi}$ using transparent $\mathrm{Scotch}^{\mathrm{TM}}$ tape, which was then mounted onto a glass slide with $20 \mu \mathrm{L}$ of tap water. Brightfield photographs were taken with the Keyence Biorevo BZ-9000 and BZII Viewer software (Keyence, Osaka, Japan) using the 10x magnification objective. Conidia shape (length and width, area, and perimeter) was determined using the ImageJ (https://imagej.nih.gov) function Analyze Particles.

Conidia germination assay. Conidia from 7-10-days-old powdery mildew colonies were blown onto $1 \%$ agar-agar Kobe I (Carl Roth, Karlsruhe, Germany). Conidia germination was assessed via brightfield microscopy at $6 \mathrm{hpi}$, scoring the percentage of spores that formed primary germ tubes and counting the number of germ tubes on germinated conidia.

Whole transcriptome shotgun sequencing analysis. Epiphytic fungal material was collected as described in (61) at $6 \mathrm{hpi}$ (appressorium formation) and $18 \mathrm{hpi}$ (early penetration). Whole transcriptome shotgun sequencing (RNA sequencing) was done by the service provider CeGaT (CeGaT, Tübingen, Germany), yielding 100-bp pairedend reads. Raw reads were trimmed using Trimmomatic v0.36 (62) and quality control of the reads was done with FastQC v0.11.5 (Babraham Bioinformatics, UK). HISAT2 (63) with '-max-intronlen $500-\mathrm{k} 1$ ' mapped the reads to the Bgh DH14 reference genome (13) and the $H$. vulgare reference transcriptome IBSC_PGSB_r1_HighConf 
(version May2016; downloaded from https://webblast.ipkgatersleben.de/barley_ibsc/downloads/). The SAM/BAM files were parsed with SAMtools v1.3.2 (64) and BEDtools v2.26.0 (65). Non-expressed genes were removed with a cutoff of FPKM $<1$ in any sample. Differential expression analysis was performed via the limma-VOOM pipeline with cutoffs log-fold-change $>|1|$ and $P_{\text {adj }}<0.05$ (66). Differential expression of selected genes was verified by qRT-PCR, performed as in (61); primers are listed in Supplementary Table 12.

\section{Quantitative real-time polymerase chain reaction} (qRT-PCR). Detached barley leaves were placed on 1\% agaragar Kobe I (Carl Roth, Karlsruhe, Germany) plates containing $85 \mu \mathrm{M}$ benzimidazole, and inoculated with $B g h$ isolates K1, SK1, SK2, and SK3, respectively. Epidermal peelings were collected at 0,6 , and 18 hpi in three biological replicates, and flash-frozen in liquid nitrogen. RNA extraction was performed using the TRIzol protocol (InvitrogenThermo Fisher, Waltham, MA, USA). RNA concentration was determined using Nanodrop 2000c (Thermo Fisher Scientific) and RNA integrity was assessed on a $2 \%$ agarose gel. Genomic DNA removal was done via DNase I (RNasefree, Thermo Fisher Scientific). Complementary DNA (cDNA) was synthesized using the High-Capacity RNA-tocDNA Kit (Applied Biosystems-Thermo Fisher) and stored at $-20{ }^{\circ} \mathrm{C}$ until further use. qRT-PCR was performed using the Takyon No ROX SYBR MasterMix blue dTTP Kit (Eurogentec, Seraing, Belgium) and the LightCycler 480 II (Roche, Rotkreuz, Switzerland). 1:10-diluted cDNA was used as a template for qRT-PCR reactions. The PCR efficiency of all primers used in this study (Supplementary Table 11) was between 1.8 and 2.0 and the annealing temperature was set to $58{ }^{\circ} \mathrm{C}$. Evaluation of expression levels of target genes in relation to the housekeeping gene BghGAPDH (61) was performed using the $\triangle \mathrm{CT}$ method (67), calculated as $2^{-(\mathrm{CT}(\text { target })-\mathrm{CT}(G A P D H))}$. Each biological replicate was measured in technical triplicates.

Genome sequencing and analysis. High molecular weight genomic DNA from barley powdery mildew conidia was generated according to (68) with the modifications indicated in (13). DNA shotgun sequencing was performed using Illumina NovaSeq technology with $1 \mu \mathrm{g}$ input DNA at the service provider CeGaT (CeGaT, Tübingen, Germany), yielding 150-bp paired-end reads. Long-read sequencing by MinION (Oxford Nanopore Technologies, Oxford, US) technology and genome assembly of Bgh SK1 were done as in (13). Single Nucleotide Polymorphisms (SNPs), insertions, and deletions (indels) were detected with FreeBayes v1.3.1-dirty (69) and raw SNPs and indels were filtered using VCFtools v0.1.16 (70) and bcftools v1.9 (https://samtools.github.io/bcftools/bcftools.html) according to (19). We used SnpEff v4.3t (build 2017-11-24 10:18) (71) to identify SNPs and indels in genic loci with predicted effects, and manually inspected candidate polymorphisms with Integrative Genomics Viewer (IGV) browser v2.6 (72). Genome mapping coverage was determined with BEDtools v2.26.0 (65). Gene losses and gene alleles were verified by Taq polymerase-based polymerase chain reaction (PCR) on genomic DNA; primers are listed in Supplementary Table 12.

Phylogenetic and functional analysis. Orthologues of Aspergillus fumigatus and Bgh medA were identified using BlastP (https://blast.ncbi.nlm.nih.gov/Blast.cgi) at $\mathrm{E}$ value < 1E-25. Protein alignments were done with ClustalW in MEGAX (73) and visualized using Jalview2 (74). The phylogenetic tree building was facilitated by Phylogeny Analysis at http://www.phylogeny.fr, with 100 bootstrap replications and otherwise default parameters. Functional predictions were done with InterProScan (https://www.ebi.ac.uk/interpro/), NCBI CDART (www.ncbi.nlm.nih.gov/Structure/lexington/lexington.cgi), PROSITE (https://www.expasy.org/resources/prosite), and protein disorder by IUPRED3 (75). Protein structures were visualized with YASARA (http://www.yasara.org); structural comparison of BLGH_06723 was performed against E3 ubiquitin-protein ligase parkin of Rattus norvegicus (10.2210/pdb4K95/pdb/ (76)).

Statistical analysis. The statistics program R v4.1.0 (77) (R foundation, www.r-project.org) was used for statistical analysis and plotting. Based on the nature of our data, which shows a non-normal distribution, unequal variance, and consists of small sample sizes (usually $n=5$ independent replicates unless mentioned otherwise), statistical analyses were conducted by Generalized Linear Modeling (GLM) (78).

Data availability. All raw RNA and DNA sequencing data generated in this study are deposited at https://www.ebi.ac.uk/ena under project IDs PRJEB36770 (Bgh K1 (13)) and at https://www.ncbi.nlm.nih.gov/sra under BioProject ID PRJNA639160. The draft genome assembly for $B g h$ SK1 has been deposited at DDBJ/ENA/GenBank under the accession JAJOCF000000000.

\section{ACKNOWLEDGEMENTS}

Seeds of the wheat cultivars used in this study were kindly provided by the late Patrick Schweizer (IPK Gatersleben, Germany) and Beat Keller (Zurich University, Switzerland). We thank Bernd Denecke (IZKF Aachen) for permitting access to the Illumina NextSeq sequencer and the Agilent Bioanalyzer platform. We acknowledge Alexander Vogel, Bianca Reiß, and Björn Usadel (RWTH Aachen University) for access to DNA quantification via Qubit. The analysis was performed with computing resources granted by RWTH Aachen University under project ID rwth0146.

This study was supported by the RWTH Aachen Excellence Initiative [RWTH fellow grant to R.P.] and funded by the Deutsche Forschungsgemeinschaft (DFG, German Research Foundation) project number 274444799 [grant 861/14-1 awarded to R.P.] in the context of the DFG-funded priority program SPP1819 "Rapid evolutionary adaptation - potential and constraints".

\section{AUTHOR CONTRIBUTIONS}

R.P. and S.K. designed the study; R.P., L.F., and S.K. were responsible for experiment conception. L.P. generated Bgh SK1, L.F. and M.B. Bgh SK2 and SK3. S.K., B.D.L., and K.D.W. performed the pathogen assays, H.W. conducted the alloxan assay. L.F. generated the samples for RNA-seq, S.K. analyzed the quantitative data and the RNA-seq data. S.K., L.F. and M.B. prepared high molecular weight genomic DNA of the Bgh strains. L.F., M.B., and S.K. performed genome assemblies, comparative genomics, and subsequent data analysis. F.K. sampled and isolated RNA for qRT-PCR, performed qRT-PCR, and cloned the BLGH_06013 alleles. S.K. wrote the first draft of the manuscript and S.K. and R.P. edited the manuscript; L.F. provided critical feedback on the drafts. All authors read the manuscript and approved the final version.

\section{COMPETING FINANCIAL INTERESTS}

The authors declare no competing financial and nonfinancial interests. 
bioRxiv preprint doi: https://doi.org/10.1101/2021.12.09.471931; this version posted December 9, 2021. The copyright holder for this preprint

(which was not certified by peer review) is the author/funder, who has granted bioRxiv a license to display the preprint in perpetuity. It is made available under aCC-BY-NC 4.0 International license.

\section{Bibliography}

1. Dieter Ebert and Peter D. Fields. Host-parasite co-evolution and its genomic signature. Nature Reviews Genetics, 21(12):754-768, dec 2020. ISSN 1471-0056. doi: 10.1038/ s41576-020-0269-1.

2. H. H. Flor. Current status of the gene-for-gene concept. Annual Review of Phytopathology, 9(1):275-296, 1971. ISSN 0066-4286. doi: 10.1146/annurev.py.09.090171.001423.

3. Jonathan D. G. Jones and Jeffery L. Dangl. The plant immune system. Nature, 444(7117): 323-329, 2006. ISSN 0028-0836. doi: 10.1038/nature05286.

4. James K. M. Brown. Durable resistance of crops to disease: A Darwinian perspective. Annual Review of Phytopathology, 53:513-539, 2015. ISSN 0066-4286. doi: 10.1146/ annurev-phyto-102313-045914.

5. Xunli Lu, Barbara Kracher, Isabel M. L. Saur, Saskia Bauer, Simon R. Ellwood, Roger P. Wise, Takashi Yaeno, Takaki Maekawa, and Paul Schulze-Lefert. Allelic barley MLA immune receptors recognize sequence-unrelated avirulence effectors of the powdery mildew pathogen. Proceedings of the National Academy of Sciences of the United States of America, 113(42):E6486-E6495, 2016. ISSN 0027-8424. doi: 10.1073/pnas.1612947113.

6. Isabel ML Saur, Saskia Bauer, Barbara Kracher, Xunli Lu, Lamprinos Franzeskakis, Marion C. Müller, Björn Sabelleck, Florian Kümmel, Ralph Panstruga, Takaki Maekawa, and Paul Schulze-Lefert. Multiple pairs of allelic MLA immune receptor-powdery mildew AVRA effectors argue for a direct recognition mechanism. eLife, 8:e44471, feb 2019. ISSN 2050084X. doi: 10.7554/eLife.44471.

7. Dinah Qutob, Jennifer Tedman-Jones, Suomeng Dong, Kuflom Kuflu, Hai Pham, Yuanchao Wang, Daolong Dou, Shiv D. Kale, Felipe D. Arredondo, Brett M. Tyler, and Mark Gijzen. Copy number variation and transcriptional polymorphisms of Phytophthora sojae RXLR effector genes Avr1a and Avr3a. PLOS ONE, 4(4):e5066, apr 2009. ISSN 1932-6203. doi: 10.1371/journal.pone.0005066.

8. Fanny E. Hartmann and Daniel Croll. Distinct trajectories of massive recent gene gains and losses in populations of a microbial eukaryotic pathogen. Molecular Biology and Evolution, 34(11):2808-2822, nov 2017. ISSN 0737-4038. doi: 10.1093/molbev/msx208.

9. Aurélien Tellier, Stefany Moreno-Gámez, and Wolfgang Stephan. Speed of adaptation and genomic footprints of host-parasite coevolution under arms race and trench warfare dynamics. Evolution, 68:2211-2224, may 2014. ISSN 00143820. doi: 10.1111/evo.12427.

10. Thorsten Langner, Adeline Harant, Luis B. Gomez-Luciano, Ram K. Shrestha, Angus Malmgren, Sergio M. Latorre, Hernán A. Burbano, Joe Win, and Sophien Kamoun. Genomic rearrangements generate hypervariable mini-chromosomes in host-specific isolates of the blast fungus. PLOS Genetics, 17(2):e1009386, feb 2021. ISSN 1553-7404. doi: 10.1371/journal.pgen.1009386.

11. Suomeng Dong, Sylvain Raffaele, and Sophien Kamoun. The two-speed genomes of filamentous pathogens: Waltz with plants. Current Opinion in Genetics and Development, 35: 57-65, 2015. ISSN 18790380. doi: 10.1016/j.gde.2015.09.001.

12. Sylvain Raffaele, Rhys A. Farrer, Liliana M. Cano, David J. Studholme, Daniel MacLean, Marco Thines, Rays H. Y. Jiang, Michael C. Zody, Sridhara G. Kunjeti, Nicole M. Donofrio, Blake C. Meyers, Chad Nusbaum, and Sophien Kamoun. Genome evolution following host jumps in the Irish potato famine pathogen lineage. Science (New York, N.Y.), 330(6010): 1540-1543, dec 2010. ISSN 0036-8075. doi: 10.1126/science.1193070.

13. Lamprinos Frantzeskakis, Barbara Kracher, Stefan Kusch, Makoto Yoshikawa-Maekawa, Saskia Bauer, Carsten Pedersen, Pietro D. Spanu, Takaki Maekawa, Paul Schulze-Lefert, and Ralph Panstruga. Signatures of host specialization and a recent transposable element burst in the dynamic one-speed genome of the fungal barley powdery mildew pathogen. BMC Genomics, 19(1):381, dec 2018. ISSN 1471-2164. doi: 10.1186/s12864-018-4750-6.

14. Marion C. Müller, Coraline Rosalie Praz, Alexandros G. Sotiropoulos, Fabrizio Menardo, Lukas Kunz, Seraina Schudel, Simone Oberhänsli, Manuel Poretti, Andreas Wehrli, Salim Bourras, Beat Keller, and Thomas Wicker. A chromosome-scale genome assembly reveals a highly dynamic effector repertoire of wheat powdery mildew. New Phytologist, 221(4): 2176-2189, mar 2019. ISSN 0028-646X. doi: 10.1111/nph.15529.

15. Pietro D. Spanu, James C. Abbott, Joëlle Amselem, Timothy A. Burgis, Darren M. Soanes, Kurt Stüber, Emiel Ver Loren van Themaat, James K. M. Brown, Sarah A. Butcher, Sarah J. Gurr, Marc-Henri Lebrun, Christopher J. Ridout, Paul Schulze-Lefert, Nicholas J. Talbot, Nahal Ahmadinejad, Christian Ametz, Geraint R. Barton, Mariam Benjdia, Przemyslaw Bidzinski, Laurence V. Bindschedler, Maike Both, Marin T. Brewer, Lance Cadle-Davidson, Molly M. Cadle-Davidson, Jerome Collemare, Rainer Cramer, Omer Frenkel, Dale Godfrey, James Harriman, Claire Hoede, Brian C. King, Sven Klages, Jochen Kleemann, Daniela Knoll, Prasanna S. Koti, Jonathan Kreplak, Francisco J. López-Ruiz, Xunli Lu, Takaki Maekawa, Siraprapa Mahanil, Cristina O. Micali, Michael G. Milgroom, Giovanni Montana, Sandra Noir, Richard J. O'Connell, Simone Oberhänsli, Francis Parlange, Carsten Pedersen, Hadi Quesneville, Richard Reinhardt, Matthias Rott, Soledad Sacristán, Sarah M. Schmidt, Moritz Schön, Pari Skamnioti, Hans Sommer, Amber E. Stephens, Hiroyuki Takahara, Hans Thordal-Christensen, Marielle Vigouroux, Ralf Weßling, Thomas Wicker, and Ralph Panstruga. Genome expansion and gene loss in powdery mildew fungi reveal tradeoffs in extreme parasitism. Science (New York, N.Y.), 330(6010):1543-1546, 2010. ISSN 1095-9203. doi: 10.1126/science.1194573.

16. Uwe Braun and R. T. A. Cook. Taxonomic manual of the Erysiphales (Powdery Mildews). CBS-KNAW Fungal Biodiversity Centre, Utrecht, The Netherlands, 2012.

17. Dean A. Glawe. The powdery mildews: a review of the world's most familiar (yet poorly known) plant pathogens. Annual Review of Phytopathology, 46:27-51, 2008. ISSN 00664286. doi: 10.1146/annurev.phyto.46.081407.104740.

18. Ralph A. Dean, Jan A. L. Van Kan, Zacharias A. Pretorius, Kim E. Hammond-Kosack, Antonio Di Pietro, Pietro D. Spanu, Jason J. Rudd, Marty Dickman, Regine Kahmann, Jeff Ellis, and Gary D. Foster. The Top 10 fungal pathogens in molecular plant pathology. Molecular Plant Pathology, 13(4):414-430, 2012. ISSN 14646722. doi: 10.1111/j.1364-3703.2011. 00783.x.

19. Mirna Barsoum, Stefan Kusch, Lamprinos Frantzeskakis, Ulrich Schaffrath, and Ralph Panstruga. Ultraviolet mutagenesis coupled with next-generation sequencing as a method for functional interrogation of powdery mildew genomes. Molecular Plant-Microbe Interactions, 33(8):1008-1021, jul 2020. ISSN 0894-0282. doi: 10.1094/mpmi-02-20-0035-ta.
20. Stefan Kusch and Ralph Panstruga. Mlo-based resistance: An apparently universal "weapon" to defeat powdery mildew disease. Molecular Plant-Microbe Interactions, 30(3): 179-189, 2017. ISSN 0894-0282. doi: 10.1094/MPMI-12-16-0255-CR.

21. Jørgen Helms Jørgensen. Discovery, characterization and exploitation of Mlo powdery mildew resistance in barley. Euphytica, 63:141-152, 1992. ISSN 1573-5060.

22. Alessandra Devoto, H. Andreas Hartmann, Pietro Piffanelli, Candace Elliott, Carl Simmons, Graziana Taramino, Chern-Sing Goh, Fred E. Cohen, Brent C. Emerson, Paul SchulzeLefert, and Ralph Panstruga. Molecular phylogeny and evolution of the plant-specific seventransmembrane MLO family. Journal of Molecular Evolution, 56(1):77-88, 2003. ISSN 0022-2844. doi: 10.1007/s00239-002-2382-5.

23. Rainer Büschges, Karin Hollricher, Ralph Panstruga, Guus Simons, Marietta Wolter, Adrie Frijters, Raymond van Daelen, Theo A. J. Van Der Lee, Paul Diergaarde, John Groenendijk, Sonja Töpsch, Pieter Vos, Francesco Salamini, and Paul Schulze-Lefert. The barley Mlo gene: A novel control element of plant pathogen resistance. Cell, 88(5):695-705, 1997. ISSN 00928674. doi: 10.1016/S0092-8674(00)81912-1.

24. Min Chul Kim, Ralph Panstruga, Candace Elliott, Judith Müller, Alessandra Devoto, Hae W. Yoon, Hyeong C. Park, Moo Je Cho, and Paul Schulze-Lefert. Calmodulin interacts with MLO protein to regulate defence against mildew in barley. Nature, 416(6879):447-451, 2002. ISSN 0028-0836. doi: $10.1038 / 416447 \mathrm{a}$

25. Andreas Freialdenhoven, Christoph Peterhänsel, Joachim Kurth, Fritz Kreuzaler, and Paul Schulze-Lefert. Identification of genes required for the function of non-race-specific $\mathrm{mlo}$ resistance to powdery mildew in barley. The Plant Cell, 8(1):5-14, 1996. ISSN 1040-4651. doi: $10.1105 /$ tpc.8.1.5

26. Nicholas C. Collins, Hans Thordal-Christensen, Volker Lipka, Stephan Bau, Erich Kombrink, Jin-Long Qiu, Ralph Hückelhoven, Mónica Stein, Andreas Freialdenhoven, Shauna C. Somerville, and Paul Schulze-Lefert. SNARE-protein-mediated disease resistance at the plant cell wall. Nature, 425(6961):973-977, 2003. ISSN 0028-0836. doi: 10.1038/ nature02076.

27. Volker Lipka, Jan Dittgen, Paweł Bednarek, Riyaz A. Bhat, Marcel Wiermer, Mónica Stein, Jörn Landtag, Wolfgang Brandt, Sabine Rosahl, Dierk Scheel, Francisco Llorente, Antonio Molina, Jane E. Parker, Shauna C. Somerville, and Paul Schulze-Lefert. Pre- and postinvasion defenses both contribute to nonhost resistance in Arabidopsis. Science (New York, N.Y.), 310(5751):1180-1183, 2005. ISSN 1095-9203. doi: 10.1126/science.1119409.

28. Mónica Stein, Jan Dittgen, Clara Sánchez-Rodríguez, Bi-Huei Hou, Antonio Molina, Paul Schulze-Lefert, Volker Lipka, and Shauna C. Somerville. Arabidopsis PEN3/PDR8, an ATP binding cassette transporter, contributes to nonhost resistance to inappropriate pathogens that enter by direct penetration. The Plant Cell, 18(3):731-746, 2006. ISSN 1040-4651. doi: $10.1105 /$ tpc. 105.038372 .

29. Erik Schwarzbach. Heat induced susceptibility of mlo-barley to powdery mildew (Blumeria graminis D.C. f.sp. hordei Marchal). Czech Journal of Genetics and Plant Breeding, 37(3): 82-87, 2001. ISSN 1212-1975.

30. A. C. Newton and I. M. Young. Temporary partial breakdown of Mlo-resistance in spring barley by the sudden relief of soil water stress. Plant Pathology, 45(5):973-977, 1996. ISSN 0032-0862. doi: 10.1111/j.1365-3059.1996.tb02908.x.

31. Michael F. Lyngkiær, H. P. Jensen, and H. Østergård. A Japanese powdery mildew isolate with exceptionally large infection efficiency on mlo-resistant barley. Plant Pathology, 44(5): 786-790, 1995. ISSN 0032-0862. doi: 10.1111/j.1365-3059.1995.tb02736.x.

32. Jørgen Helms Jørgensen and Martin Wolfe. Genetics of powdery mildew resistance in barley. Critical Reviews in Plant Sciences, 13(1):97-119, 1994. ISSN 0735-2689. doi: 10.1080/07352689409701910.

33. Morten N. Grell, Kirsten B. Holm, and Henriette Giese. Two novel Blumeria graminis f. sp. hordei genes are induced in planta and up-regulated in mlo virulent isolates. Physiological and Molecular Plant Pathology, 66(3):79-89, 2005. ISSN 08855765. doi: 10.1016/j.pmpp. 2005.05.001.

34. Jantine Lammechine Atzema. Durability of mlo resistance in barley against powdery mildew caused by Erysiphe graminis f.sp. hordei. Ph.d. thesis, ETH Zürich, Zürich, Switzerland, 1998.

35. Erik Schwarzbach. Recessive total resistance of barley to mildew (Erysiphe graminis D.C. f. sp. hordei Marchal) as a mutation induced by ethylmethansulfonate. Genetika a šlechtění, 3:159-162, 1967. ISSN 1212-1975.

36. Anja Reinstädler, Judith Müller, Jerzy H. Czembor, Pietro Piffanelli, and Ralph Panstruga. Novel induced mlo mutant alleles in combination with site-directed mutagenesis reveal functionally important domains in the heptahelical barley Mlo protein. BMC Plant Biology, 10(1): 31, 2010. ISSN 1471-2229. doi: 10.1186/1471-2229-10-31.

37. Takashi Yaeno, Miki Wahara, Mai Nagano, Hikaru Wanezaki, Hirotaka Toda, Hiroshi Inoue, Ayaka Eishima, Masamichi Nishiguchi, Hiroshi Hisano, Kappei Kobayashi, Kazuhiro Sato, and Naoto Yamaoka. RACE1, a Japanese Blumeria graminis f. sp. hordei isolate, is capable of overcoming partially m/o-mediated penetration resistance in barley in an allele-specific manner. PLOS ONE, 16(8):e0256574, aug 2021. ISSN 1932-6203. doi: 10.1371/journal. pone.0256574.

38. Hongpo Wu, Weiwei Zhang, Martin Schuster, Marcin Moch, Reinhard Windoffer, Gero Steinberg, Christopher J. Staiger, and Ralph Panstruga. Alloxan disintegrates the plant cytoskeleton and suppresses mlo-mediated powdery mildew resistance. Plant and Cell Physiology, 61(3):505-518, mar 2020. ISSN 0032-0781. doi: 10.1093/pcp/pcz216.

39. Sabine Seeholzer, Takashi Tsuchimatsu, Tina Jordan, Stéphane Bieri, Simone Pajonk, Wenxiang Yang, Ahmed Jahoor, Kentaro K. Shimizu, Beat Keller, and Paul Schulze-Lefert. Diversity at the Mla powdery mildew resistance locus from cultivated barley reveals sites of positive selection. Molecular Plant-Microbe Interactions, 23(4):497-509, apr 2010. ISSN 0894-0282. doi: 10.1094/MPMI-23-4-0497.

40. Daniela Nowara, Alexandra Gay, Christophe Lacomme, Jane Shaw, Christopher J. Ridout, Dimitar Douchkov, Götz Hensel, Jochen Kumlehn, and Patrick Schweizer. HIGS: hostinduced gene silencing in the obligate biotrophic fungal pathogen Blumeria graminis. The Plant Cell, 22(9):3130-3141, 2010. ISSN 1040-4651. doi: 10.1105/tpc.110.077040.

41. Fabrice N. Gravelat, Daniele E. Ejzykowicz, Lisa Y. Chiang, Josée C. Chabot, Mirjam Urb, K. Denyese Macdonald, Nadia Al-Bader, Scott G. Filler, and Donald C. Sheppard. Aspergillus fumigatus MedA governs adherence, host cell interactions and virulence. Cellular 
bioRxiv preprint doi: https://doi.org/10.1101/2021.12.09.471931; this version posted December 9, 2021. The copyright holder for this preprint (which was not certified by peer review) is the author/funder, who has granted bioRxiv a license to display the preprint in perpetuity. It is made available under aCC-BY-NC 4.0 International license.

Microbiology, 12(4):473-488, apr 2010. ISSN 14625814. doi: 10.1111/j.1462-5822.2009. 01408.x.

42. Qusai Al Abdallah, Se-In Choe, Paolo Campoli, Stefanie Baptista, Fabrice N. Gravelat, Mark J. Lee, and Donald C. Sheppard. A conserved C-terminal domain of the Aspergillus fumigatus developmental regulator MedA is required for nuclear localization, adhesion and virulence. PLOS ONE, 7(11):e49959, nov 2012. ISSN 1932-6203. doi: 10.1371/journal.pone.0049959.

43. Beatriz Manriquez, Daniel Muller, and Claire Prigent-Combaret. Experimental evolution in plant-microbe systems: A tool for deciphering the functioning and evolution of plantassociated microbial communities. Frontiers in Microbiology, 12:896, may 2021. ISSN 1664-302X. doi: 10.3389/fmicb.2021.619122.

44. Matthew E. Humphry, Chiara Consonni, and Ralph Panstruga. mlo-based powdery mildew immunity: Silver bullet or simply non-host resistance? Molecular Plant Pathology, 7(6): 605-610, 2006. ISSN 14646722. doi: 10.1111/j.1364-3703.2006.00362.x.

45. Christoph Peterhänsel, Andreas Freialdenhoven, Joachim Kurth, R. Kolsch, and Paul Schulze-Lefert. Interaction analyses of genes required for resistance responses to powdery mildew in barley reveal distinct pathways leading to leaf cell death. The Plant Cell, 9 (8):1397-1409, 1997. ISSN 1040-4651.

46. Erik Schwarzbach. Response to selection for virulence against the $\mathrm{ml}$-o based mildew resistance in barley, not fitting the gene-for-gene hypothesis. Barley Genetics Newsletter, 9:85-89, 1979.

47. Fabrizio Menardo, Coraline Rosalie Praz, Stefan Wyder, Roi Ben-David, Salim Bourras, Hiromi Matsumae, Kaitlin Elyse McNally, Francis Parlange, Andrea Riba, Stefan Roffler, Luisa Katharina Schaefer, Kentaro K. Shimizu, Luca Valenti, Helen Zbinden, Thomas Wicker, and Beat Keller. Hybridization of powdery mildew strains gives rise to pathogens on novel agricultural crop species. Nature Genetics, 48(2):201-205, 2016. ISSN 1546-1718. doi: $10.1038 / n g .3485$.

48. Thomas Wicker, François Sabot, Aurélie Hua-Van, Jeffrey L. Bennetzen, Pierre Capy, Boulos Chalhoub, Andrew Flavell, Philippe Leroy, Michele Morgante, Olivier Panaud, Etienne Paux, Phillip SanMiguel, and Alan H. Schulman. A unified classification system for eukaryotic transposable elements. Nature Reviews Genetics, 8(12):973-982, dec 2007. ISSN 1471-0056. doi: $10.1038 / \mathrm{nrg} 2165$.

49. Kasey Rodgers and Mitch McVey. Error-prone repair of DNA double-strand breaks. Journa of Cellular Physiology, 231(1):15-24, jan 2016. ISSN 00219541. doi: 10.1002/jcp. 25053.

50. Howard H. Y. Chang, Nicholas R. Pannunzio, Noritaka Adachi, and Michael R. Lieber. Nonhomologous DNA end joining and alternative pathways to double-strand break repair. $\mathrm{Na}$ ture Reviews Molecular Cell Biology, 18(8):495-506, aug 2017. ISSN 1471-0072. doi $10.1038 / \mathrm{nrm} .2017 .48$

51. Promita Bose, Karen E. Hermetz, Karen N. Conneely, and M. Katharine Rudd. Tandem repeats and G-rich sequences are enriched at human CNV breakpoints. PLOS ONE, 9(7): e101607, jul 2014. ISSN 1932-6203. doi: 10.1371/journal.pone.0101607.

52. Lisenka E.L.M. Vissers, Samarth S. Bhatt, Irene M. Janssen, Zhilian Xia, Seema R. Lalani, Rolph Pfundt, Katarzyna Derwinska, Bert B.A. de Vries, Christian Gilissen, Alexander Hoischen, Monika Nesteruk, Barbara Wisniowiecka-Kowalnik, Marta Smyk, Han G. Brunner, Sau Wai Cheung, Ad Geurts van Kessel, Joris A. Veltman, and Pawel Stankiewicz. Rare pathogenic microdeletions and tandem duplications are microhomology-mediated and stimulated by local genomic architecture. Human Molecular Genetics, 18(19):3579-3593, oct 2009. ISSN 1460-2083. doi: $10.1093 / \mathrm{hmg} / \mathrm{ddp} 306$.

53. Claudia M. B. Carvalho and James R. Lupski. Mechanisms underlying structural variant formation in genomic disorders. Nature Reviews Genetics, 17(4):224-238, apr 2016. ISSN 1471-0056. doi: 10.1038/nrg.2015.25.

54. P. J. Hastings, Grzegorz Ira, and James R. Lupski. A microhomology-mediated breakinduced replication model for the origin of human copy number variation. PLoS Genetics, 5 (1):e1000327, jan 2009. ISSN 1553-7404. doi: 10.1371/journal.pgen.1000327.

55. Pawel Stankiewicz and James R. Lupski. Genome architecture, rearrangements and genomic disorders. Trends in Genetics, 18(2):74-82, feb 2002. ISSN 01689525. doi: 10.1016/S0168-9525(02)02592-1.

56. Celia Payen, Romain Koszul, Bernard Dujon, and Gilles Fischer. Segmental duplications arise from Pol32-dependent repair of broken forks through two alternative replication-based mechanisms. PLoS Genetics, 4(9):e1000175, sep 2008. ISSN 1553-7404. doi: 10.1371/ journal.pgen.1000175.

57. Cynthia J. Sakofsky, Sandeep Ayyar, Angela K. Deem, Woo-Hyun Chung, Grzegorz Ira and Anna Malkova. Translesion polymerases drive microhomology-mediated break-induced replication leading to complex chromosomal rearrangements. Molecular Cell, 60(6):860872, dec 2015. ISSN 10972765. doi: 10.1016/j.molcel.2015.10.041.

58. Thomas Wicker, Simone Oberhänsli, Francis Parlange, Jan P. Buchmann, Margarita Shatalina, Stefan Roffler, Roi Ben-David, Jaroslav Doležel, Hana Šimková, Paul SchulzeLefert, Pietro D. Spanu, Rémy Bruggmann, Joëlle Amselem, Hadi Quesneville, Emiel Ver Loren van Themaat, Timothy Paape, Kentaro K. Shimizu, and Beat Keller. The wheat powdery mildew genome shows the unique evolution of an obligate biotroph. Nature Genetics, 45(9):1092-1096, 2013. ISSN 1546-1718. doi: 10.1038/ng.2704.

59. Thomas Badet and Daniel Croll. The rise and fall of genes: Origins and functions of plant pathogen pangenomes. Current Opinion in Plant Biology, 56:65-73, aug 2020. ISSN 13695266. doi: 10.1016/j.pbi.2020.04.009.

60. Lamprinos Frantzeskakis, Stefan Kusch, and Ralph Panstruga. The need for speed: compartmentalized genome evolution in filamentous phytopathogens. Molecular Plant Pathology, 20(1):3-7, jan 2019. ISSN 14646722. doi: 10.1111/mpp.12738.

61. Helen G. Pennington, Linhan Li, and Pietro D. Spanu. Identification and selection of normalization controls for quantitative transcript analysis in Blumeria graminis. Molecular Plant Pathology, 17(4):625-633, 2015. ISSN 14646722. doi: 10.1111/mpp.12300.

62. Anthony M. Bolger, Marc Lohse, and Björn Usadel. Trimmomatic: A flexible trimmer for Illumina sequence data. Bioinformatics (Oxford, England), 30(15):2114-2120, 2014. ISSN 1367-4803. doi: 10.1093/bioinformatics/btu170.

63. Daehwan Kim, Ben Langmead, and Steven L. Salzberg. HISAT: a fast spliced aligner with low memory requirements. Nature Methods, 12(4):357-360, apr 2015. ISSN 1548-7091. doi: $10.1038 /$ nmeth. 3317 .
64. Heng Li, Bob Handsaker, Alec Wysoker, Tim Fennell, Jue Ruan, Nils Homer, Gabor Marth, Goncalo Abecasis, and Richard Durbin. The Sequence Alignment/Map format and SAMtools. Bioinformatics (Oxford, England), 25(16):2078-2079, 2009. ISSN 1367-4803. doi: 10.1093/bioinformatics/btp352.

65. Aaron R. Quinlan and Ira M. Hall. BEDTools: A flexible suite of utilities for comparing genomic features. Bioinformatics (Oxford, England), 26(6):841-842, mar 2010. ISSN 14602059. doi: 10.1093/bioinformatics/btq033.

66. Charity W. Law, Yunshun Chen, Wei Shi, and Gordon K. Smyth. voom: Precision weights unlock linear model analysis tools for RNA-seq read counts. Genome Biology, 15(2):R29, 2014. ISSN 1465-6914. doi: 10.1186/gb-2014-15-2-r29.

67. Kenneth J. Livak and Thomas D. Schmittgen. Analysis of relative gene expression data using real-time quantitative PCR and the $2^{-\Delta \Delta C T}$ method. Methods, 25(4):402-408, dec 2001. ISSN 10462023. doi: 10.1006/meth.2001.1262.

68. Joanna M. Feehan, Katherine E. Scheibel, Salim Bourras, William Underwood, Beat Keller, and Shauna C. Somerville. Purification of high molecular weight genomic DNA from powdery mildew for long-read sequencing. Journal of Visualized Experiments: JoVE, (121): e55463, mar 2017. ISSN 1940-087X. doi: 10.3791/55463.

69. Erik Garrison and Gabor Marth. Haplotype-based variant detection from short-read sequencing. arXiv, jul 2012.

70. Petr Danecek, Adam Auton, Goncalo Abecasis, Cornelis A. Albers, Eric Banks, Mark A. DePristo, Robert E. Handsaker, Gerton Lunter, Gabor T. Marth, Stephen T. Sherry, Gilean McVean, and Richard Durbin. The variant call format and VCFtools. Bioinformatics, 27(15): 2156-2158, aug 2011. doi: 10.1093/bioinformatics/btr330.

71. Pablo Cingolani, Adrian Platts, Le Lily Wang, Melissa Coon, Tung Nguyen, Luan Wang, Susan J. Land, Xiangyi Lu, and Douglas M. Ruden. A program for annotating and predicting the effects of single nucleotide polymorphisms, SnpEff: SNPs in the genome of Drosophila melanogaster strain w1118; iso-2; iso-3. Fly, 6(2):80-92, apr 2012. doi: 10.4161/fly.19695.

72. James T. Robinson, Helga Thorvaldsdóttir, Aaron M. Wenger, Ahmet Zehir, and Jill P. Mesirov. Variant review with the Integrative Genomics Viewer. Cancer Research, 77(21): e31-e34, nov 2017. doi: 10.1158/0008-5472.CAN-17-0337.

73. Sudhir Kumar, Glen Stecher, and Koichiro Tamura. MEGA7: Molecular Evolutionary Genetics Analysis version 7.0 for bigger datasets. Molecular Biology and Evolution, 33(7): 1870-1874, 2016. ISSN 0737-4038. doi: 10.1093/molbev/msw054.

74. Andrew M. Waterhouse, James B. Procter, David M. A. Martin, Michèle Clamp, and Geoffrey J. Barton. Jalview Version 2 - a multiple sequence alignment editor and analysis workbench. Bioinformatics, 25(9):1189-1191, may 2009. ISSN 1367-4803. doi: 10.1093/bioinformatics/btp033.

75. Gábor Erdős, Mátyás Pajkos, and Zsuzsanna Dosztányi. IUPred3: Prediction of protein disorder enhanced with unambiguous experimental annotation and visualization of evolutionary conservation. Nucleic Acids Research, 49(W1):W297-W303, jul 2021. ISSN 03051048. doi: $10.1093 /$ nar/gkab408.

76. Jean-François Trempe, Véronique Sauve, Karl Grenier, Marjan Seirafi, Matthew Y. Tang, Marie Ménade, Sameer Al-Abdul-Wahid, Jonathan Krett, Kathy Wong, Guennadi Kozlov, Bhushan Nagar, Edward A. Fon, and Kalle Gehring. Structure of parkin reveals mechanisms for ubiquitin ligase activation. Science, 340(6139):1451-1455, jun 2013. ISSN 0036-8075 doi: $10.1126 /$ science. 1237908 .

77. R Core Team. R: A language and environment for statistical computing. $R$ Foundation for Statistical Computing, Vienna, Austria, 2018. ISSN 3-900051-07-0.

78. Michael J. Crawley. Statistics: An introduction using R. John Wiley \& Sons, Ltd, Imperial College London, UK, second edition, 2015. ISBN 978-1-118-94109-6. 


\section{Supplementary data}

Supplementary Table 1. RNA-seq mapping statistics.

Supplementary Table 2. Differential expression analysis results of Hordeum vulgare mlo-3 at 6 hpi with Bgh SK1 and K1.

Supplementary Table 3. Differential expression analysis results of Hordeum vulgare mlo-3 at 18 hpi with Bgh SK1 and K1.

Supplementary Table 4. Annotations of differentially expressed genes in Hordeum vulgare mlo-3 at 18 hpi.

Supplementary Table 5. Differential expression analysis results of Bgh SK1 compared to Bgh K1 on Hordeum vulgare mlo-3 at $6 \mathrm{hpi}$.

Supplementary Table 6. Differential expression analysis results of Bgh SK1 compared to Bgh K1 on Hordeum vulgare mlo-3 at 18 hpi.

Supplementary Table 7. Annotations of differentially expressed genes in Bgh SK1 at 18 hpi.

Supplementary Table 8. Whole genome shotgun DNA sequencing mapping statistics.

Supplementary Table 9. List of SNVs detected and manually inspected in K1 Aachen, SK1, SK2, and SK3.

Supplementary Table 10. Genome assembly statistics for Bgh SK1 compared to publicly available B. graminis f.sp. hordei genome assemblies.

Supplementary Table 11. NCBI CDART results for the protein BLGH_02703.

Supplementary Table 12. List of oligonucleotides used in this study. 